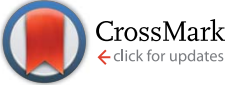

Cite this: RSC Adv., 2016, 6, 22161

Received 28th January 2016

Accepted 18th February 2016

DOI: $10.1039 / c 6 r a 02638 a$

www.rsc.org/advances

\title{
Revisiting oxime-nitrone tautomerism. Evidence of nitrone tautomer participation in oxime nucleophilic addition reactions $\uparrow$
}

\author{
David Roca-López, Andrea Darù, Tomás Tejero and Pedro Merino*
}

\begin{abstract}
The oxime-nitrone tautomerism has been revisited using high-level DFT calculations. The isomerization has been found to be more favorable through a bimolecular process involving two molecules of oxime, a finding that argues against the commonly accepted thermal 1,2- $\mathrm{H}$-shift mechanism. The reaction of arylamidoximes with 1,2-diaza-1,3-dienes to yield the corresponding $O$-substituted oximes (stable intermediates for the synthesis of 1,2,4-oxadiazine derivatives) was also investigated as a rare case in which $\mathrm{O}$-alkylation is observed in the reaction between oximes and electron-poor alkenes in the absence of a base. Under such conditions the reaction usually proceeds through the nucleophilic attack of the oxime nitrogen to yield the corresponding nitrone. The computational investigation revealed that in the case of arylamidoximes, the pathway involving the less stable but more reactive nitrone tautomer is the predominant mechanism, evidencing for the first time the involvement of a nitrone tautomer in nucleophilic additions of oximes. Validation of the model has been carried out by studying alternative ene-like processes; the dramatically different reactivity predicted for arylamidoximes and unsubstituted oxime are rationalized in terms of steric hindrance.
\end{abstract}

\section{Introduction}

About 40 years ago, Vijfhuizen and Terlouw reported the first evidence, observed by mass spectrometry, of the oxime-nitrone isomerization (Scheme 1). ${ }^{1}$ Two years later, Dignam and Hegarty studied isomerization of oximes in aqueous solution as a function of the $\mathrm{pH}$ and concluded that at high $\mathrm{pH}$ values the reactive species is the neutral oxime rather than the nitrone tautomer. ${ }^{2}$ In 1984, Grigg and co-workers proposed that isomerization of oxime to nitrone consisted of a thermal 1,2-hydrogen shift. ${ }^{3}$

Since these early reports, cycloaddition reactions of oximes towards isoxazolidines have been extensively studied. ${ }^{4}$ In particular, the intramolecular version of the reaction (the socalled "intramolecular oxime olefin cycloaddition", IOOC) has received considerable attention ${ }^{5}$ in contrast to intermolecular

Laboratorio de Síntesis Asimétrica, Departamento de Síntesis y Estructura de Biomoléculas, Instituto de Síntesis Química y Catálisis Homogénea (ISQCH), Universidad de Zaragoza, CSIC, Campus San Francisco, E-50009 Zaragoza, Aragón, Spain.E-mail: pmerino@unizar.es

$\dagger$ Electronic supplementary information (ESI) available: Details on calculations corresponding to oxime-nitrone tautomerism including unimolecular $1,2-\mathrm{H}$ shift direct and promoted by neighboring groups; bimolecular mechanisms promoted by EtOH and via oxime dimer complexes. Conformational analysis and reactivity indices of 1,2-diaza-1,3-diene 6. Details on calculations corresponding to Michael addition of oximes $\mathbf{1 a}$ and $\mathbf{1 b}$ to $\mathbf{6}$. Details on calculations corresponding to ene-like processes between oxime $\mathbf{1 a}$ and $\mathbf{6}$, and oxime $\mathbf{1 b}$ and methyl 2-methylfumarate and 6. Cartesian coordinates of optimized structures. See DOI: 10.1039/c6ra02638a reactions which have been less studied. ${ }^{6}$ In this context, Tamura and co-workers developed intra- ${ }^{7}$ and intermolecular ${ }^{8}$ cycloadditions of $O$-silylated oximes that required milder conditions by using boron trifluoride etherate as a promoter of the reaction, leading to $N$-boranonitrones. Frank and co-workers reported a combined experimental and computational study demonstrating that even though the nitrone tautomer is less stable than the oxime one, the former is more reactive, leading to more stable transition structures. ${ }^{9}$ All these studies concern cycloaddition reactions of the nitrone tautomer. However, there are no reports illustrating the participation of such a tautomer in nucleophilic additions in spite of the fact that nitrones can act as excellent electrophiles. ${ }^{10}$

The mechanism of the isomerization has been discussed in various studies, ${ }^{11}$ all of them claiming for the previously proposed 1,2-hydrogen shift. Noguchi and co-workers ${ }^{12}$ found a dependence on the type of solvent but no evidences on the effect of alcoholic solvents. The authors suggested a solvation effect favoring the isomerization towards nitrone. The influence of substituents in the tautomerism has also been considered ${ }^{13}$

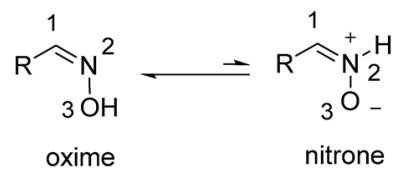

Scheme 1 Oxime-nitrone tautomerism. 
and in some particular case, a facile isomerization has been attributed to the presence of functional groups facilitating hydrogen shift. ${ }^{14}$ For instance, for 4-chlorobenzaldehyde it had been estimated that $c a .1-2 \%$ of the NH-nitrone should be present in equilibrium. ${ }^{15}$ Radom and co-workers studied computationally nitrosomethane and its nitrone and oxime isomers. ${ }^{16}$ These authors concluded that $\mathrm{NH}$-nitrones should be observable even though a barrier of $70.8 \mathrm{kcal} \mathrm{mol}^{-1}$ (MP3/6$31 \mathrm{G}++$ ) was estimated for the $1,2-\mathrm{H}$ shift between formaldoxime and formaldonitrone. A further computational study on the oxime-nitrone tautomerism was carried out by Lammertsma and co-workers, ${ }^{17}$ who demonstrated that the oxime-nitrone tautomerism is thermodynamically unfavoured. More recently, Sousa and co-workers have suggested that the population of the nitrone tautomer should be insignificant on the basis of more accurate calculations. ${ }^{18}$ However, these recent studies were only concerned with the stability of the different tautomers as well as solvent effects.

The oxime-nitrone tautomerism has important implications in reactivity. When an oxime reacts with an alkene (that can act as both dipolarophile and Michael acceptor if $\mathrm{Z}$ is an electronwithdrawing group) three products can be obtained, even though there are four possible reaction pathways (Scheme 2).

When oximes react with electron-poor alkenes $(\mathrm{Z}=\mathrm{EWG})$, in the absence of any base, the usually preferred pathway is an enelike reaction (formal Michael addition) via the nitrogen lone pair to yield $N$-alkylnitrones (Scheme 2, path A). ${ }^{6 a}$ The mechanism is expected to be concerted (through $\mathbf{T S}_{\mathbf{A}}$ ) with concomitant nucleophilic attack of the nitrogen atom and $\mathrm{H}$-transfer. In fact, the concertedness of the reaction has already been theoretically demonstrated for related additions of hydroxylamines to electron-poor alkenes. ${ }^{19}$ Usually, the in situ formed nitrones 3 react with a second molecule of alkene to give the corresponding dipolar cycloaddition (not shown in Scheme 2). On the contrary, when the alkene is unactivated, path $\mathrm{D}$ is preferred. As mentioned above, the cycloaddition reaction of the nitrone tautomer to give isoxazolidines 5 (Scheme 2, path D), through a typical concerted transition state $\mathbf{T S}_{\mathbf{D}}$, has also been reported in several instances. ${ }^{4}$ In the case of intramolecular reactions a high dependence of the stereochemistry of the oxime has been observed; whereas $E$-isomers of oximes react through path $\mathrm{A}, Z$-isomers prefer path $\mathrm{D}$ via tautomeric nitrone. ${ }^{13 c}$

Under basic conditions it is also possible to carry out the $O$-alkylation of the oxime through a typical oxa-Michael reaction. ${ }^{20}$ However, in the absence of a base the mechanism should take place through a disfavored (due to ring strain) transition state $\left(\mathbf{T S}_{\mathbf{B}}\right.$ ) leading to $O$-alkylated derivatives 4 (Scheme 2, path B). To date no evidences have been found of a fourth pathway $\mathrm{C}$ consisting of the formation of oxime ethers by nucleophilic attack of the nitrone oxygen, after isomerization of oxime into nitrone. Only two reports described the obtention of $O$-alkylated oximes by reaction with electron-poor alkenes in the absence of a base. ${ }^{4 i, 21}$ By analogy to path $\mathrm{A}\left(\mathbf{T S}_{\mathbf{A}}\right)$ the mechanism could be expected to be concerted through $\mathbf{T S}_{\mathbf{C}}$. Although it cannot be considered an ene-like reaction because the hydrogen is not allylic, the process involves a 1,4-H shift as in the case of path A.

As part of our ongoing interest in mechanistic aspects of nitrone reactivity, ${ }^{22}$ we sought to investigate the nitrone-oxime isomerization by computational DFT methods and explore the possibility of a participation of the nitrone tautomer in nucleophilic addition reactions in the absence of a base. We chose for the study the Michael addition of arylamidoximes to 1,2-diaza1,3-dienes, studied experimentally by Santeusanio and coworkers (Scheme 3). ${ }^{21}$ This reaction, carried out in the absence of a base, is a rare example of addition of oximes to electron-

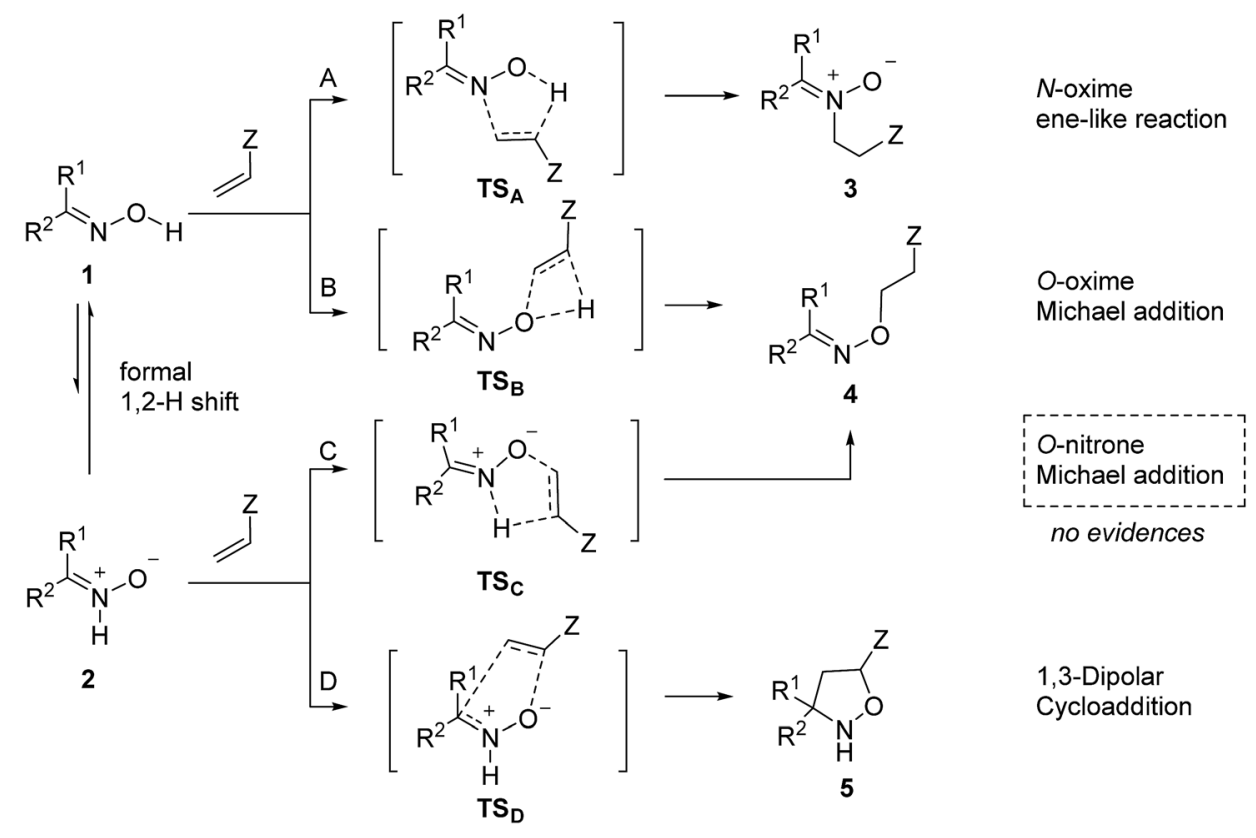

Scheme 2 Possible reaction pathways between oximes and electron-poor alkenes. 


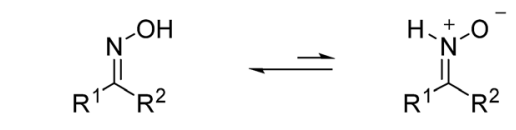

$$
\begin{array}{ll}
\text { 1a } R^{1}=R^{2}=H & \text { 2a } R^{1}=R^{2}=H \\
\text { 1b } R^{1}=P h ; R^{2}=N_{2} & \text { 2b } R^{1}=P h ; R^{2}=N_{2} \\
\text { 1c } R^{1}=N_{2} ; R^{2}=P h & \text { 2c } R^{1}=N_{2} ; R^{2}=P h
\end{array}
$$

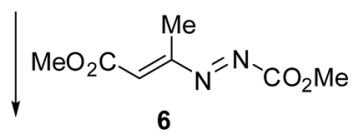

$$
\begin{aligned}
& \text { 7a } R^{1}=R^{2}=\mathrm{H} \\
& 7 b R^{1}=P h ; R^{2}=N_{2}
\end{aligned}
$$

Scheme 3 Nucleophilic addition of oximes to 1,2-diaza-1,3-dienes.

poor olefins in which $O$-alkylated oximes $\mathbf{4}$ are preferentially formed instead nitrones 3.

Under these circumstances, paths $\mathrm{B}$ and $\mathrm{C}$ could be competitive, the tautomerism prior the addition being an option. Therefore, aiming to obtain a more accurate description of the oxime-nitrone tautomerism and its implication on nucleophilic addition reactions, this paper presents proofs for a bimolecular isomerization mechanism and, for the first time, an unequivocal characterization of transition state structures in solution involving nitrone tautomers in a nucleophilic addition reaction (Scheme 2, path C).

\section{Computational methods}

All of the calculations were performed using the Gaussian09 program..$^{23}$ Molecular geometries were optimized with the M06-2X functional ${ }^{24}$ in conjunction with cc-pVTZ basis set. ${ }^{25}$ This method has been recently used successfully in theoretical investigations with nitrones. ${ }^{22 a-f}$ Analytical second derivatives of the energy were calculated to classify the nature of every stationary point, to determine the harmonic vibrational frequencies, and to provide zero-point vibrational energy corrections. The thermal and entropic contributions to the free energies were also obtained from the vibrational frequency calculations, using the unscaled frequencies. All transition structures were characterized by one imaginary frequency. All the located TSs were confirmed to connect to reactants and products by intrinsic reaction coordinate (IRC) analyses. ${ }^{26}$ The IRC paths were traced using the second order González-Schlegel integration method. ${ }^{27}$ Calculations have been carried out considering solvent effects (EtOH) with the PCM. ${ }^{28}$

We have considered two models for the study of oximenitrone isomerization: (i) the simplest oxime 1a and nitrone 2a, and (ii) the real system studied experimentally, ${ }^{22}$ consisting of oxime $(Z)-\mathbf{1 b}$ and nitrone $(Z)-\mathbf{2 b}$. For the purpose of comparison, we have also included in the study the $(E)$-isomers $1 \mathrm{c}$ and $2 \mathrm{c}$ (Scheme 3).

\section{Results and discussion}

\section{Starting materials}

We first computed $1 \mathbf{a}$ and both $E / Z$ isomers of oximes $\mathbf{1 b}$, $\mathbf{c}$ and nitrones $\mathbf{2 b}$, c; since the reaction was carried out in $\mathrm{EtOH}$, we chose this solvent for our studies. In the case of oximes, the anti conformer was the most stable; in fact, the corresponding syn oximes could not be located because all calculations converged to the most stable anti oximes. The optimized geometries of compounds 1a-c and 2a-c are given in Fig. 1.

Calculations predict the $Z$-isomer to be more stable than the $E$-isomer. In the case of oximes, isomer (Z)-1b is $5.8 \mathrm{kcal} \mathrm{mol}^{-1}$ more stable than $(E)-\mathbf{1 c}$; for nitrones $(Z)-\mathbf{2 b}$ is $6.9 \mathrm{kcal} \mathrm{mol}^{-1}$ more stable than $(E)$-2c. Both $(Z)$-isomers present a hydrogen bond between the amino group and the oxygen atom $(d=2.15 \AA$ and $2.21 \AA$ for $\mathbf{1 b}$ and $\mathbf{2 b}$, respectively). A weaker interaction $(d=$ $2.45 \AA$ ) is also observed for $(E)$-1c between the amino group and the oxime nitrogen. All $Z$ and $E$ isomers $\mathbf{1 b}$, $\mathbf{c}$ and $2 \mathbf{b}$, c deviate the phenyl ring from planarity because of the steric hindrance of the phenyl ring. Larger torsion angles are present for $(E)$-isomers than for $(Z)$-isomers $\left(\mathrm{C}_{\mathrm{Ar} 2}-\mathrm{C}_{\mathrm{Ar} 1}-\mathrm{C}_{\mathrm{Ox}}-\mathrm{N}_{\mathrm{ox}}: 53.8^{\circ}\right.$ for (E)-1c vs. $27.5^{\circ}$ for $(Z)-\mathbf{1 b}$. $\mathrm{C}_{\mathrm{Ar} 2}-\mathrm{C}_{\mathrm{Ar} 1}-\mathrm{C}_{\text {nit }}-\mathrm{N}_{\text {nit }}: 35.0^{\circ}$ for $(E)-2 \mathrm{c} v s$. $26.4^{\circ}$ for $\left.(Z)-2 \mathbf{b}\right)$. When compared oxime $\mathbf{1 b}$ and nitrone $2 \mathbf{b}$, the former resulted to be more stable by $9.2 \mathrm{kcal} \mathrm{mol}^{-1}$ in agreement with experimental observations. The $E / Z$ isomerization of oximes and nitrones has been studied in previous reports and it is well document that it can take place through energy barriers of ca. $10 \mathrm{kcal} \mathrm{mol}^{-1}$ for oximes ${ }^{29}$ and $25 \mathrm{kcal} \mathrm{mol}^{-1}$ for nitrones. $^{21 b}$

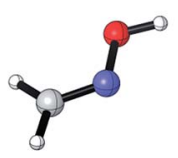

$1 \mathrm{a}$

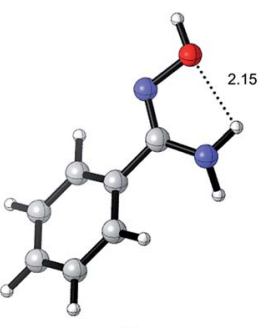

$1 b$

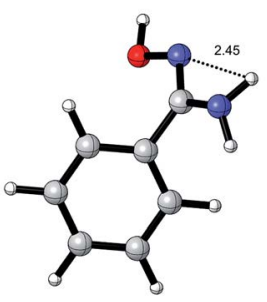

$1 \mathrm{c}$

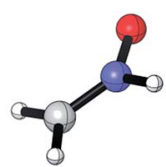

$2 a$

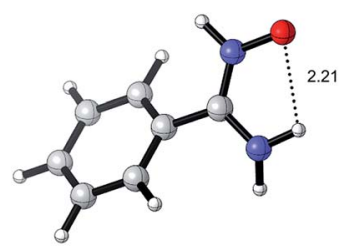

$2 b$

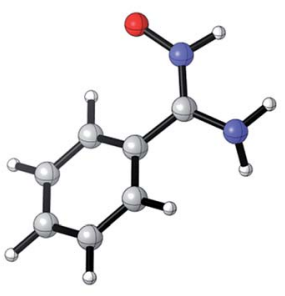

2c
Fig. 1 Optimized transition structures (M06-2X/cc-pVTZ/PCM = $\mathrm{EtOH}$ ) of oximes $1 \mathrm{a}-\mathrm{c}$ and nitrones $2 \mathrm{a}-\mathrm{c}$. Distances are given in angstrom. 


\section{Oxime-nitrone tautomerism}

Grigg and co-workers initially suggested that 1,2-prototropy in oximes should be a facile process. ${ }^{30}$ On the other hand, the same authors also mentioned that it is a high energy process when compared with other reactions such as formal Michael additions (actually, ene-like reactions), ${ }^{6 \boldsymbol{a}}$ thus explaining the observed behavior in the presence of electron-poor olefins (Scheme 2, path A). With other olefins the isomerization is well demonstrated by trapping the NH-nitrone through a dipolar cycloaddition (Scheme 2, path D). ${ }^{4}$ Since the early proposal of the 1,2-prototropic route by Grigg and co-workers, ${ }^{3}$ all authors have assumed this rationale ${ }^{\mathbf{1 1}}$ in spite of such isomerization mechanism had been discarded by Radom and co-workers 30 years ago. ${ }^{\mathbf{1 6}}$ In fact, that study considered location of transition structure TS1a for the 1,2-H shift between 1a and 2a (Scheme 4) and assigned a barrier to the process of $70.8 \mathrm{kcal}$ $\mathrm{mol}^{-1} \cdot{ }^{16}$ We also located TS1a in gas phase (Table 1) and considering ethanol as solvent at our standard level of theory (M06-2X/cc-pVTZ). The results for the reaction in EtOH are summarized in Table 2. The geometry of TS1a is given in Fig. 2.

The calculated barrier for the isomerization in gas phase was $54.7 \mathrm{kcal} \mathrm{mol}^{-1}$. The observed difference of $c a .20 \mathrm{kcal} \mathrm{mol}^{-1}$ with the value obtained by Radom and co-workers in the $80{ }^{\prime} \mathbf{s}^{16}$ can be attributed to the use of M06-2X functional which slightly underestimate activation parameters. ${ }^{31}$ In any case the obtained results give a good illustration of the reaction mechanism pointing out that the process would require a high energy to take place.

When considering solvent effects (EtOH) the barrier for TS1a (53.2 kcal mol $\mathrm{m}^{-1}$ ) is similar to that found in gas phase. The corresponding TS1b starting from $\mathbf{1 b}$ to form $\mathbf{2 b}$ was also located and a barrier of $49.5 \mathrm{kcal} \mathrm{mol}^{-1}$ was found (Table 2). The transition structure (TS1c) corresponding to the transformation of less stable 1c to form 2c was also located and a higher barrier $\left(56.4 \mathrm{kcal} \mathrm{mol}^{-1}\right)$ was obtained for the process. In any case, high energies ( $c a .50 \mathrm{kcal} \mathrm{mol}^{-1}$ ) are required by the process to take place.

The geometries of the transition structures are given in Fig. 2. Similar distances for hydrogen shift are found in all cases. The $\mathrm{N}-\mathrm{H}$ distances (1.11-1.13 $\mathrm{A}$ ) are shorter than the $\mathrm{O}-\mathrm{H}$ distances (1.28-1.31 $\mathrm{\AA})$. The 1,2-H shift takes place in the plane of the oxime for TS1a and TS1c (H-O1-N2-C3 dihedral angle of $180.0^{\circ}$ and $174.7^{\circ}$ for TS1a and TS1c, respectively). On the other hand for TS1b the 1,2-H shift takes place out of the plane of the oxime ( $\mathrm{H}-\mathrm{O} 1-\mathrm{N} 2-\mathrm{C} 3$ dihedral angle of $\left.132^{\circ}\right)$. This deviation is due to the existing $\mathrm{H}$-bond interaction between an oxygen lone

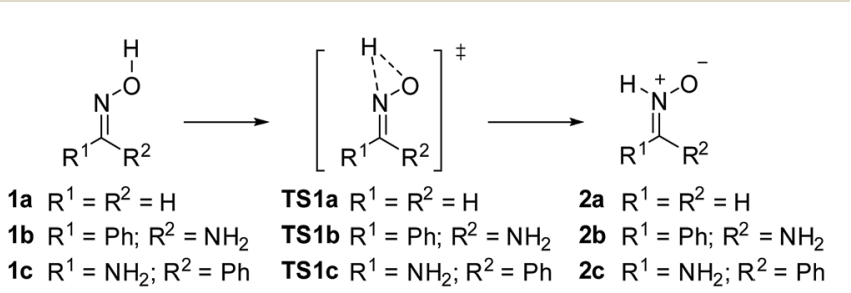

Scheme 4 1,2-Shift mechanism of oxime-nitrone isomerization.
Table 1 Calculated absolute (hartrees) and relative (kcal $\mathrm{mol}^{-1}$ ) energies in gas phase of the stationary points corresponding to isomerization of $1 \mathrm{a}$ into $2 \mathrm{a}$ via $1,2-\mathrm{H}$ shift

\begin{tabular}{|c|c|c|c|c|}
\hline & \multicolumn{2}{|c|}{ M06-2X/cc-pVTZ } & \multicolumn{2}{|c|}{$\mathrm{MP} 3 / 6-31 \mathrm{G}++^{a}$} \\
\hline & $G$ & $\Delta G^{b}$ & $G$ & $\Delta G^{b}$ \\
\hline $1 \mathrm{a}$ & -169.787344 & 0.0 & -169.34926 & 0.0 \\
\hline TS1a & -169.700184 & 54.7 & -169.23702 & 70.8 \\
\hline $2 \mathbf{a}$ & -169.765342 & 13.8 & -169.31409 & 22.2 \\
\hline
\end{tabular}

pair and the amino group, which is not present in TS1c. Whereas TS1a is, obviously, completely planar, in TS1b and TS1c the phenyl ring is out the plane formed by the nitrone and amino moieties (by $25^{\circ}$ and $43^{\circ}$ in TS1b and TS1c, respectively).

It has been suggested that neighboring groups at the periphery of the oxime could promote a more favorable $1,5-\mathrm{H}$ shift in detriment of the assumed 1,2-H shift. This possibility has been exemplified with monoximes of 1,2,3-triketones, ${ }^{32}$ alk2-enylamino-substituted pyrans ${ }^{12}$ and pyrido[1,2- $a$ ]pyrimidines. ${ }^{13 a, 14}$ In the case of oxime $\mathbf{1 b}$ we also explored a similar option by considering the intramolecular protonation of the amino group and further 1,3-H sigmatropic shift (Scheme 5).

According to the calculated mechanism, illustrated in Scheme 5, the isomerization should take place starting from oxime 1b. The initial $\mathrm{H}$-transfer from oxyme to $\alpha$-amino group takes place along the reaction path in an early stage without formation of any stationary point. The first transition state found in the reaction path corresponds to rotation of the $\mathrm{C}-\mathrm{N}$ bond. The IRC showed a temporary pyramidalization of $\mathrm{C}$ atom with concomitant transformation of the $\mathrm{C}=\mathrm{N}-\mathrm{O}^{-}$system into $\mathrm{a}^{-} \mathrm{C}-\mathrm{N}=\mathrm{O}$ one during the rotation (see ESI $\dagger$ ). This rotation is required to achieve the correct orientation of the nitrogen lone pair to receive the proton from the amino group in the second step. In fact, such geometry is that found in intermediate $\mathbf{8}$ whose zwitterionic nature was confirmed by its large dipole moment $(11.6 \mathrm{D})$. The formation of intermediate 8 is the ratelimiting step. Further evolution of 8 takes place through a $1,3-\mathrm{H}$

Table 2 Calculated (M06-2X/cc-pVTZ/PCM = EtOH) absolute (hartrees) and relative ( $\mathrm{kcal} \mathrm{mol}^{-1}$ ) energies of the stationary points corresponding to isomerization of $1 \mathrm{a}-\mathrm{c}$ into $2 \mathrm{a}-\mathrm{c}$ via $1,2-\mathrm{H}$ shift

\begin{tabular}{lrr}
\hline & $\Delta E_{0}{ }^{a}$ & $\Delta G^{a}$ \\
\hline 1a & 0.0 & 0.0 \\
TS1a & 53.1 & 53.2 \\
2a & 9.8 & 10.0 \\
1b & 0.0 & 0.0 \\
TS1b & 49.6 & 49.5 \\
2b & 9.1 & 9.2 \\
1c & 6.2 & 5.8 \\
TS1c & 56.8 & 56.4 \\
2c & 15.9 & 16.1 \\
${ }^{a}$ Referred to 1a or 1b. & &
\end{tabular}




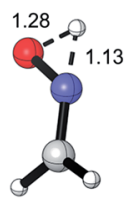

TS1a

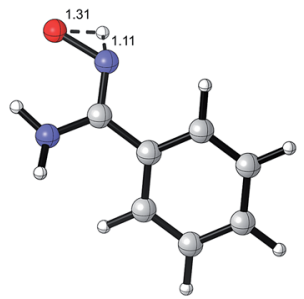

TS1b

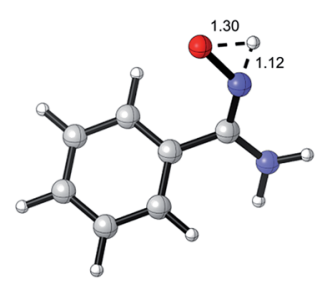

TS1c
Fig. 2 Optimized transition structures (M06-2X/cc-pVTZ/PCM = $\mathrm{EtOH}$ ) corresponding to 1,2-H shift between oximes 1 and nitrones 2 . Distances are given in angstrom

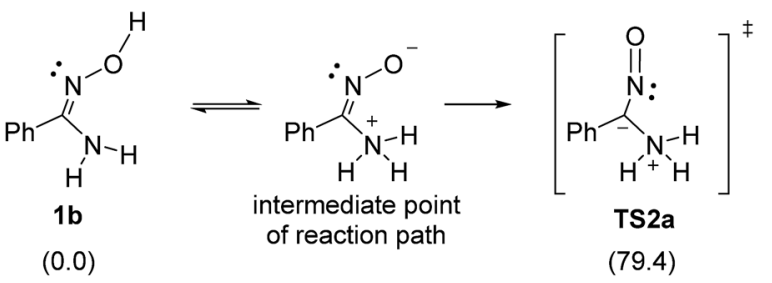

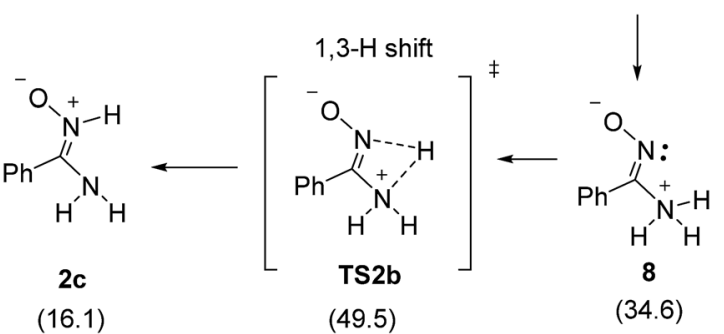

Scheme 5 1,2-H shift promoted by neighboring groups. Relative energies (M06-2X/cc-pVTZ/PCM $=\mathrm{EtOH})$ are given in $\mathrm{kcal} \mathrm{mol}^{-1}$, between brackets.

shift (TS2b), to yield nitrone 2c (for a complete analysis of the reaction including detailed IRCs and geometries of stationary points see ESI $\dagger)$. The first barrier $\left(79.4 \mathrm{kcal} \mathrm{mol}^{-1}\right)$ corresponding to TS2a is too high to consider this mechanism as a possibility.

Next, we considered the possibility of bimolecular mechanisms. In the presence of a protic solvent as ethanol, a solvent molecule can transfer a proton to the nitrogen atom while receiving a different one from the oxime moiety, according to the mechanism illustrated in Scheme 6.

Similar results were obtained for the model system (series a) and for the real ones (series $\mathbf{b}$ and $\mathbf{c}$ ). After formation of an initial complex between the oxime and a molecule of ethanol, promoted by H-bonding as depicted in Scheme 6, exchange of protons through TS3 give rise to a new complex between ethanol and nitrone leading to isomerized nitrone 2 . The corresponding transition structures and the initial and final complexes formed with ethanol were calculated. The results are summarized in Table 3.

In the bimolecular process the formation of an initial complex should be stabilized by H-bonding. At the same time, the loss of translational entropy is much higher than in a unimolecular process; consequently, the value of free energy is

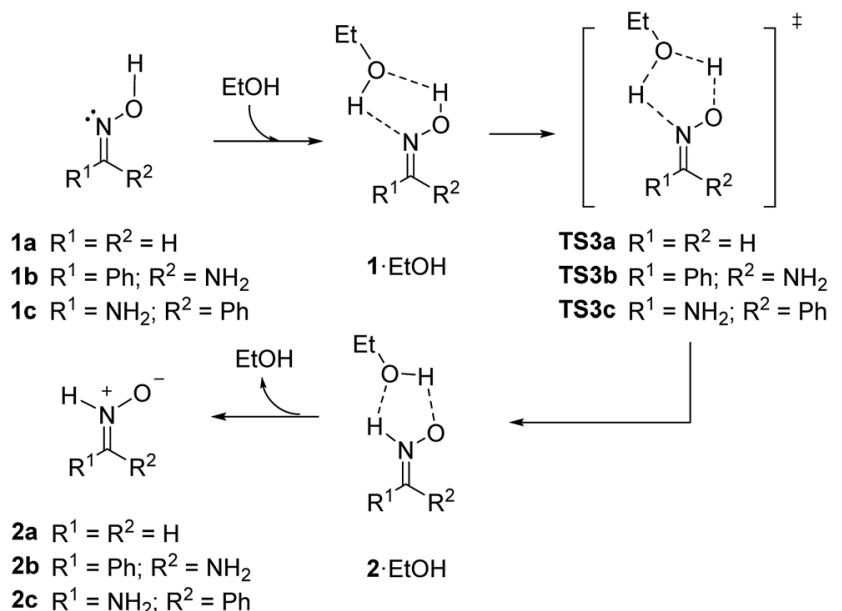

Scheme 6 Ethanol-catalyzed bimolecular isomerization of oxime 1 into nitrone 2 (M06-2X/cc-pVTZ/PCM = EtOH).

markedly overestimated. ${ }^{33}$ Because of it, in order to compare the stability of reagents and products with initial and final complexes, it is more advisable to consider electronic energy $\left(E_{0}\right)$ rather than free energy $(G)$ where the entropic factor is introduced..$^{34}$ According to $E_{0}$ values, complexes $\mathbf{1} \cdot \mathrm{EtOH}$ are $c a$. 5-7 kcal mol ${ }^{-1}$ more stable than the corresponding isolated oximes ( $5.5 \mathrm{kcal} \mathrm{mol}^{-1}$ for $\mathbf{1 a}, 6.5 \mathrm{kcal} \mathrm{mol}^{-1}$ for $\mathbf{1 b}$ and $7.0 \mathrm{kcal}$ $\mathrm{mol}^{-1}$ for 1c). Complexes $2 \cdot \mathrm{EtOH}$ are about $7-9 \mathrm{kcal} \mathrm{mol}^{-1}$ more stable than the parent isolated nitrones $\left(6.8 \mathrm{kcal} \mathrm{mol}^{-1}\right.$ for 2a, $9.2 \mathrm{kcal} \mathrm{mol}^{-1}$ for $2 \mathbf{b}$ and $9.3 \mathrm{kcal} \mathrm{mol}^{-1}$ for $2 \mathbf{c}$ ).

Once formed the complex the isomerization takes place in the single entity oxime-EtOH to form the nitrone-EtOH entity, as in a unimolecular reaction, so the relative activation entropy

Table 3 Calculated (M06-2X/cc-pVTZ/PCM = EtOH) absolute (hartrees) and relative ( $\mathrm{kcal} \mathrm{mol}^{-1}$ ) energies of the stationary points corresponding to isomerization of 1 into 2 promoted by a discrete molecule of $\mathrm{EtOH}$

\begin{tabular}{lrr}
\hline & $\Delta E_{0}{ }^{a}$ & \multicolumn{1}{c}{$\Delta G^{a}$} \\
\hline 1a & 0.0 & 0.0 \\
1a·EtOH & -5.5 & 4.1 \\
TS3a & 16.1 & 27.1 \\
2a·EtOH & 3.0 & 12.5 \\
2a & 9.8 & 10.0 \\
1b & 0.0 & 0.0 \\
1b·EtOH & -6.5 & 3.4 \\
TS3b & 13.2 & 24.5 \\
2b·EtOH & -0.1 & 10.0 \\
2b & 9.1 & 9.2 \\
1c & 6.2 & 5.8 \\
1c· EtOH & -0.8 & 9.1 \\
TS3c & 19.0 & 30.1 \\
2c· EtOH & 6.6 & 16.8 \\
2c & 15.9 & 16.1
\end{tabular}

${ }^{a}$ Referred to 1a or $\mathbf{1 b}$; a discrete molecule of EtOH $\left(\Delta E_{0}=-154.950425\right.$ hartrees; $\Delta G=-154.975812$ hartrees) has been considered when necessary. 
should be close to zero and Gibbs energy can be adequately considered for evaluating the barrier of the process. Once formed the initial complex TS3 controls the rate of the reaction. Similar energy barriers were found in all cases $\left(27.1 \mathrm{kcal} \mathrm{mol}^{-1}\right.$ for the model $1 \mathrm{a} / 2 \mathrm{a}$ and $24.5 \mathrm{kcal} \mathrm{mol}^{-1}$ for the most stable $Z$-isomer $(\mathbf{1 b} / \mathbf{2 b})$ of the real system). The obtained values were $30 \mathrm{kcal} \mathrm{mol}^{-1}$ lower than the unimolecular process discussed above. The geometry of the transition structures TS3a-c showed some differences between the model and the real system (Fig. 3). For TS3a similar distances were found between heteroatoms and hydrogens (1.26-1.28 $\AA$ ) with the only exception of the shorter $\mathrm{O}_{\mathrm{EtOH}}-\mathrm{H}$ distance of $1.17 \AA$. In the case of TS3b and TS3c the distance O1-H (1.09 $\AA$ in both) was slightly shorter than the N2-H distance (1.12 $\AA$ in both). However, the distance between hydrogens and the oxygen atom of the ethanol molecule was much longer (1.41-1.47 ̊). The spatial disposition of hydrogen atoms and heteroatoms were rather similar in all transition structures TS3. The higher stability of TS3b over TS3c is due to the extra H-bond interaction between $\mathrm{O} 1$ and the amino group.

The isomerization also takes place in aprotic solvents and under a variety of conditions. Consequently, it is plausible to consider, independently of the environment, a bimolecular mechanism in which only two molecules of oxime/nitrone are exclusively involved (Scheme 7). Again, formation of initial and final complexes should be considered. The corresponding transition structures and the initial and final complexes were calculated. The results are summarized in Table 4 . The geometries of the transition structures are given in Fig. 4 (for geometries of complexes see ESI $\dagger$ ).

By considering $E_{0}$ values as mentioned above, complexes 1.1 are more stable than the corresponding isolated oximes (8.6 kcal mol${ }^{-1}$ for $1 \mathrm{a}, 11.1 \mathrm{kcal} \mathrm{mol}^{-1}$ for $\mathbf{1 b}$ and $5.3 \mathrm{kcal} \mathrm{mol}^{-1}$ for 1c). Complexes $2 \mathbf{a} \cdot 2 \mathbf{a}$ and $2 \mathbf{c} \cdot 2 \mathbf{c}$ are about $2 \mathrm{kcal} \mathrm{mol}^{-1}$ more stable than the parent isolated nitrones $\left(1.6\right.$ and $1.8 \mathrm{kcal} \mathrm{mol}^{-1}$ for $2 \mathrm{a}$ and $2 \mathrm{c}$, respectively). A greater difference ( $6.3 \mathrm{kcal} \mathrm{mol}^{-1}$ ) was observed between complex $\mathbf{2 b} \cdot \mathbf{2} \mathbf{b}$ and the isolated nitrone 2b. Again, the responsible for this difference is the $\mathrm{H}$-bond interaction present in $\mathbf{2} \mathbf{b}$.

The isomerization from $1 \mathbf{a} \cdot \mathbf{1 a}$ to $2 \mathbf{a} \cdot \mathbf{2 a}$ is endergonic by 16.7 $\mathrm{kcal} \mathrm{mol}^{-1}$ with an energy barrier (TS4a) of $18.7 \mathrm{kcal} \mathrm{mol}^{-1}$ from the ground state. In the case of the real system, the formation of two $(Z)$-nitrones from two molecules of $(Z)$-oxime is endergonic

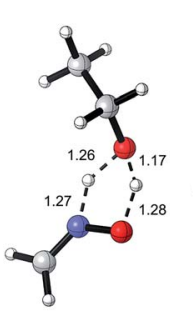

TS3a
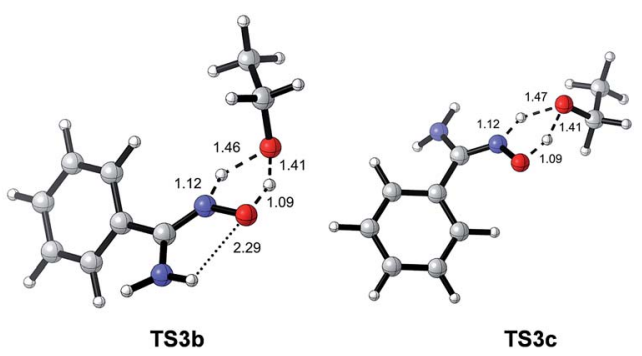

Fig. 3 Optimized transition structures (M06-2X/cc-pVTZ/PCM = $\mathrm{EtOH})$ corresponding to isomerization of 1 into 2 promoted by a discrete molecule of EtOH. Distances are given in angstrom.

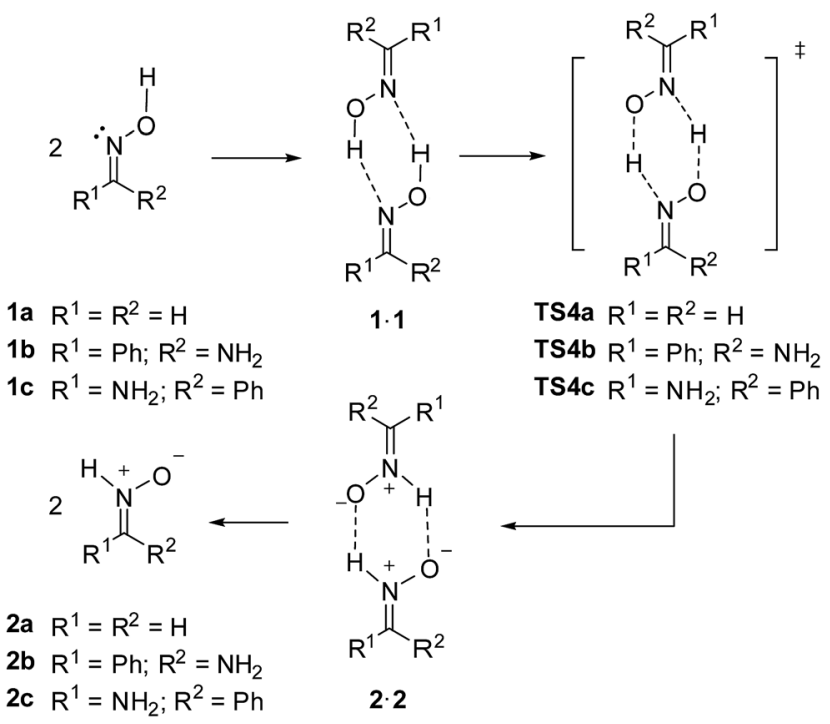

Scheme 7 Bimolecular mechanism involving exclusively two molecules of oxime/nitrone.

by $14.5 \mathrm{kcal} \mathrm{mol}^{-1}$. Calculations predicted a barrier (TS4b) of $15.3 \mathrm{kcal} \mathrm{mol}^{-1}$ which is a lower value than those obtained for 1,2-H shift (79.4 kcal $\left.\mathrm{mol}^{-1}\right)$, and intramolecular- and $\mathrm{EtOH}$ assisted isomerizations $\left(24.5 \mathrm{kcal} \mathrm{mol}^{-1}\right) \cdot{ }^{35}$ Similarly, if we consider the less stable $(E)$-isomers the isomerization from oximes to nitrones is endergonic by $16.8 \mathrm{kcal} \mathrm{mol}^{-1}$ with an energy barrier (TS4c) of $16.4 \mathrm{kcal} \mathrm{mol}^{-1}$.

The transition structure for the model isomerization of $\mathbf{1 a}$ into $2 \mathrm{a}$ is symmetrical with the hydrogen breaking and forming

Table 4 Calculated (M06-2X/cc-pVTZ/PCM = EtOH) absolute (hartrees) and relative ( $\mathrm{kcal} \mathrm{mol}^{-1}$ ) energies of the stationary points corresponding to isomerization of 1 into 2 through a bimolecular mechanism

\begin{tabular}{lrr}
\hline & $\Delta E_{0}{ }^{a}$ & $\Delta G^{a}$ \\
\hline 1a & 0.0 & 0.0 \\
1a·1a & -8.6 & 1.4 \\
TS4a & 7.6 & 18.7 \\
2a·2a & 8.2 & 18.1 \\
2a & 9.8 & 10.0 \\
1b & 0.0 & 0.0 \\
1b·1b & -11.1 & 0.0 \\
TS4b & 2.9 & 15.3 \\
2b·2b & 2.8 & 14.5 \\
2b & 9.1 & 9.2 \\
1c & 6.2 & 5.8 \\
1c· 1c & 0.9 & 11.9 \\
TS4c & $20.1^{b}$ & 28.2 \\
2c.2c & 17.7 & 28.7 \\
2c & 15.9 & 16.1
\end{tabular}

${ }^{a}$ Referred to $\mathbf{1 a}$ or $\mathbf{1 b}$; two molecules have been considered when necessary. ${ }^{b}$ Barrier calculated from $E$ values, without ZPVE correction. After ZPVE correction the value of the barrier is $16.7 \mathrm{kcal} \mathrm{mol}^{-1}$ revealing the introduction of an experimental error that situates $2 \mathbf{c} \cdot 2 \mathbf{c}$ above TS4. This error only affected TS4c since the rest of energy barrier values are similar after ZPVE correction. 


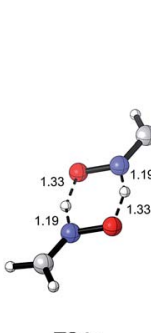

TS4a

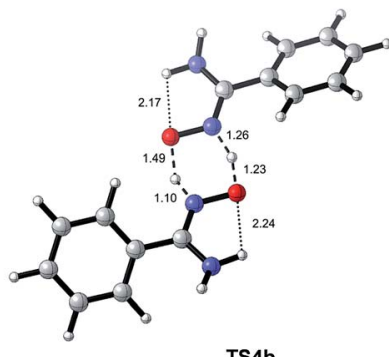

TS4b

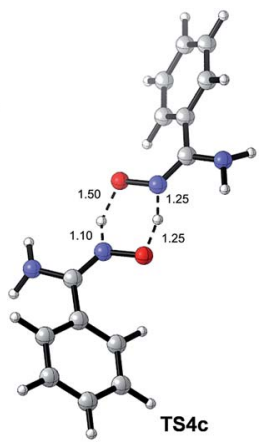

Fig. 4 Optimized transition structures (M06-2X/cc-pVTZ/PCM = $\mathrm{EtOH}$ ) corresponding to isomerization of 1 into 2 through a bimolecular mechanism. Distances are given in angstrom.

bonds at distances of $1.19 \AA$ and $1.33 \AA$ from nitrogen and oxygen atoms, respectively. The transition state is completely planar without any deviation out of plane. On the other hand, for the real system the presence of the substituents distort the symmetrical disposition of the transition structure and an asynchronous $\mathrm{H}$-exchange is observed. In fact, for $\mathbf{1 b}$ several transition structures displaying minor conformational differences were located. The most stable TS4b and TS4c are given in Fig. 4. The shortest distance $(1.10 \AA$ in both TS4b and TS4c) corresponded to one forming $\mathrm{N} 2-\mathrm{H}$ bond, the other one having a distance of $1.26 \AA$ for TS4b and $1.25 \AA$ for TS4c. The longest distances correspond to the breaking O1-H bonds $(1.49 \AA$ and $1.50 \AA$ in TS4b and TS4c, respectively) opposed to the above mentioned shortest $\mathrm{N} 2-\mathrm{H}$ forming bonds. The remaining $\mathrm{O} 1-\mathrm{H}$ breaking bonds showed distances of $1.23 \AA$ and $1.25 \AA$ in TS4b and TS4c, respectively. The hydrogen atoms and the heteroatoms involved in the proton exchange are all in the same plane without deviation. The only deviation out of the plane observed corresponded to the phenyl rings, already discussed above for both oximes and nitrones. Again, the difference in stability between TS4b and TS4c is attributed to a cooperative effect of the extra H-bonding interactions in TS4b. Such interactions are stronger (indicated by a shorter distance of $2.17 \AA$ A) in the side in which the hydrogen transfer towards the formation of the nitrone is more advanced.

In summary, these data with the simplest oxime 1a and a real system $\mathbf{1 b}$ corroborate that the oxime-nitrone isomerization is a bimolecular process involving a hydrogen transfer from an oxime molecule to another. The lowest barrier $\left(15.3 \mathrm{kcal} \mathrm{mol}^{-1}\right)$ for the isomerization has been found for the interconversion of two $(Z)$-oxime molecules into two $(Z)$-nitrone molecules; starting from $(E)$-isomers the barrier was found to be $16.4 \mathrm{kcal} \mathrm{mol}^{-1}$. Higher barriers were found for the other mechanisms investigated including unimolecular 1,2-shift (49.5 kcal mol$\left.{ }^{-1}\right)$, neighboring group-assisted $\left(79.4 \mathrm{kcal} \mathrm{mol}^{-1}\right)$ mechanisms, and bimolecular ethanol-assisted $\left(24.5 \mathrm{kcal} \mathrm{mol}^{-1}\right)$ isomerization.

\section{Michael addition of arylamidoximes to 1,2-diaza-1,3-dienes}

As mentioned above, the reaction between an oxime and an electron-poor olefin, in the absence of a base, proceeds as an ene-like reaction to yield nitrones (Scheme 2, path A). Interestingly, the reaction of oxime $\mathbf{1 b}$ with 1,2-diaza-1,3-dienes such as 6, in the absence of any base and in EtOH as a solvent, yields the corresponding $O$-alkylated oxime $7,{ }^{21}$ representing an exception to the usually observed behavior. 1,2-Diaza-1,3-dienes are wellknown as Michael acceptors in $\beta$-position to the diazo functionality ${ }^{36}$ which is the directing electron-withdrawing group. This has been corroborated by reactivity indices calculations. ${ }^{37}$ In order to investigate whether the nucleophilic addition to 6 takes place via the oxime $\mathbf{1 b}$ or the nitrone $\mathbf{2 b}$ (after isomerization) we carried out a systematic computational study of the process in which we also included the corresponding $(E)$-isomers $1 \mathbf{c}$ and $\mathbf{2 c}$ (for a preliminary study with nitrone 1a see ESI $\dagger$ ).

1,2-Diaza-1,3-dienes like 6 can adopt s-trans and s-cis conformations involving three dihedral angles. The most stable conformers (by $c a$. 4-5 kcal mol$\left.{ }^{-1}\right)^{38}$ correspond to an s-trans conformation at the central dihedral angle. ${ }^{39}$ However, the s-cis conformation might lead to stabilizing interactions that could furnish more stable situations. Because of it, both conformations have been taken into consideration. A comprehensive exploration of the PES of the reaction covering a total of 192 initial transition structures was carried out (for details see ESI $\uparrow$ ).

In principle, both the oxime $\mathbf{1 b}$ and nitrone $2 \mathbf{b}$ can react with 1,2-diaza-1,3-diene 6 through the corresponding transition structures TS5 and TS6 to provide zwitterions P1 and P2

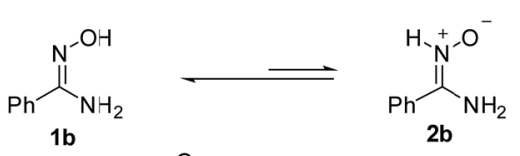

$1 \mathrm{~b}$
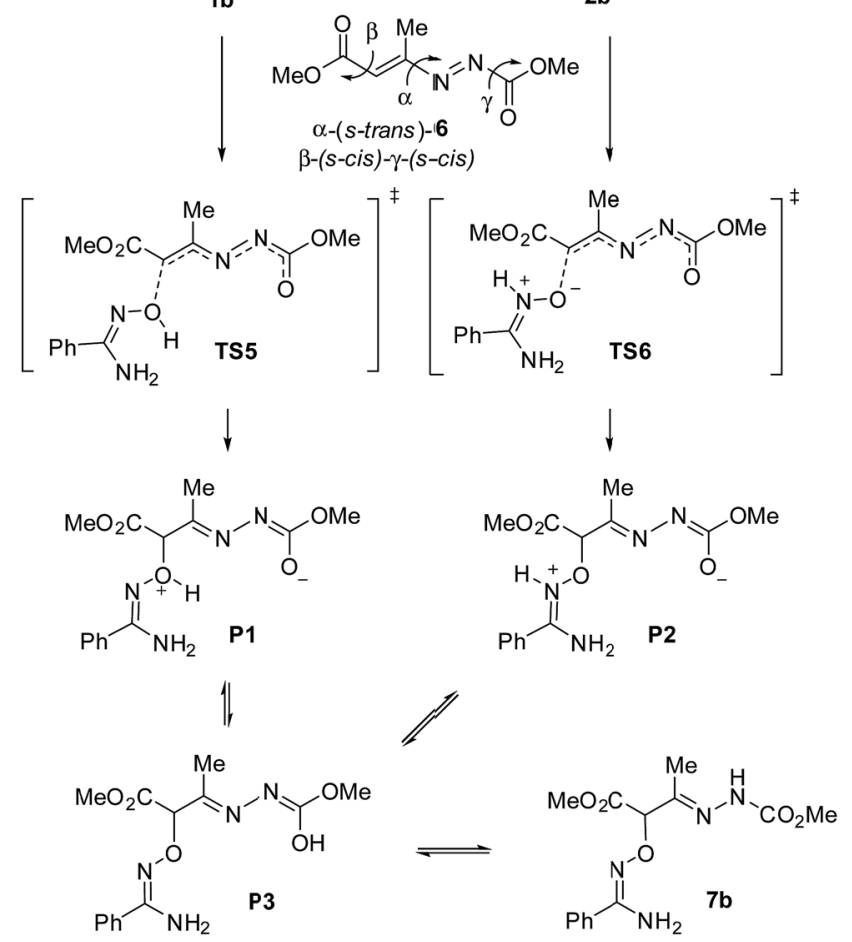

Scheme 8 Mechanisms for the reaction between $1 \mathrm{~b}$ and 6 . Only (Z)-isomers are shown. 
(Scheme 8). Further migration of the proton, through enol P3, yields the final product 7 observed experimentally. Such a migration might also occur during the formation of the new $\mathrm{C}-\mathrm{O}$ bond, depending on the interactions found in the corresponding transition structures. Of course, it will be necessary to consider energetics of the isomerization discussed in the preceding section for the full analysis of the process. Also, $E / Z$ isomerization of oxime and/or nitrone tautomer could occur during the reaction. Because of it we have included such variability in the analysis as discussed above (not shown in Scheme 8).

The above-mentioned exploratory work of the PES for the nucleophilic attack provided, after full optimization at M06-2X/ cc-pVDZ/PCM = EtOH level, 99 independent transition structures from which only 27 account for $100 \%$ of probability. Moreover, from those 27 , only 8 contribute with more than $1 \%$, accounting for $97.4 \%$ of probability. Notably, all TSs in the first 54 positions correspond to a nucleophilic attack of the nitrone tautomer, the first 17 corresponding to $(Z)-\mathbf{2 b}$. The first instance of a transition structure corresponding to the nucleophilic attack of the oxime tautomer appears at 55th position with a relative free energy of $10.9 \mathrm{kcal} \mathrm{mol}^{-1}$ (for details see ESI $\dagger$ ). Next, in order to obtain more accurate energy barriers for the reaction, we considered transition structures up to $4 \mathrm{kcal} \mathrm{mol}^{-1}$ of relative difference (19 TSs accounting for 99.8\%) and they were full optimized at the highest triple- $\zeta$ level M06-2X/cc-pVTZ/ $\mathrm{PCM}=\mathrm{EtOH}$. The results are given in Table 5. As mentioned above all transition structures correspond to the attack of nitrone (Z)-2b (Table 5, entries 1-18) with one exception that corresponds to $(E)$-2c (Table 5, entry 19), the most stable transition structure for the $(E)$-series. In order to compare the barriers of the different reaction pathways, we also included in triple- $\zeta$ optimization the most stable cases for the addition of oximes (Z)-1b and (E)-1c (Table 5, entries 20 and 21, respectively). ${ }^{40}$

The three most stable transition states TS6a-c (within a range of $0.1 \mathrm{kcal} \mathrm{mol}^{-1}$ ) and TS6j accounting for $64.7 \%$ correspond to the same approach; they only differ on variations at $\beta$ and $\gamma$ dihedral angles of the 1,2-diaza-1,3-diene 6 . The same situation is found for TS6d, $\mathbf{f}, \mathbf{h}$ and TS6e, $\mathbf{g}$, TS6i representing a different approach. In consequence, it is possible to limit the discussion by considering only 4 models, namely TS6a, TS6d, TS6e and TS6i that adequately represent 10 situations in a range of $2.0 \mathrm{kcal} \mathrm{mol}{ }^{-1}$ of relative energy, accounting for $97.9 \%$ of Bolztmann's distribution. The rest of TSs, i.e. TS6k-s, are at least $2.0 \mathrm{kcal} \mathrm{mol}^{-1}$ above the most stable TS6a and account for the remaining $2.1 \%$. The geometries of TS6a, TS6d, TS6e and TS6i are given in Fig. 5. Whereas in TS6a and TS6i the attack is carried out from the $R e$ face of the nitrone, in TS6d and TS6e, the attack comes from the $S i$ face of the nitrone. The forming bond distances are similar in all cases. TS6a and TS6e correspond to droite approaches with $\mathrm{N} 2-\mathrm{O} 1-\mathrm{C}^{\prime}-\mathrm{C} 2^{\prime}$ angles of $44.1^{\circ}$ and $13.0^{\circ}$, respectively. While $\mathbf{T 6 d}$ corresponds to a gauche approach, TS6i corresponds to an anti approach.

The four models illustrated in Fig. 5 are in a range of $1.8 \mathrm{kcal}$ $\mathrm{mol}^{-1}$, close to experimental error so, any of them could be considered valid. In any case, the favored addition through the (Z)-nitrone tautomer is fully confirmed. The addition of (E)-

Table 5 Calculated (M06-2X/cc-pVTZ/PCM = EtOH) absolute (hartrees) and relative (kcal mol ${ }^{-1}$ ) energies for the most stable transition structures of the reaction of oximes $1 b, c$ and nitrones $2 b, c$ with 1,2-diaza-1,3-diene $6^{a}$

\begin{tabular}{|c|c|c|c|c|c|c|c|c|c|c|c|}
\hline Entry & Taut. $^{b}$ & TS & Face $^{c}$ & Stag. ${ }^{d}$ & $\alpha^{e}$ & $\beta^{e}$ & $\gamma^{e}$ & $\Delta E_{0}^{f}$ & $\Delta G^{f}$ & Rel. ab. ${ }^{g}(\%)$ & Im. freq. \\
\hline 1 & $2 \mathbf{b}$ & TS6a & $R e$ & $\mathrm{~g}$ & $\mathrm{t}$ & $\mathrm{c}$ & $\mathrm{c}$ & 0.0 & 0.0 & 23.4 & -317.1 \\
\hline 2 & & TS6b & $R e$ & $\mathrm{~g}$ & $\mathrm{t}$ & $\mathrm{t}$ & $\mathrm{c}$ & 0.5 & 0.1 & 20.2 & -304.1 \\
\hline 3 & & TS6c & $R e$ & $\mathrm{~g}$ & $\mathrm{t}$ & $\mathrm{c}$ & $\mathrm{t}$ & 0.4 & 0.1 & 20.2 & -301.1 \\
\hline 4 & & TS6d & $S i$ & $\mathrm{~d}$ & $\mathrm{t}$ & $\mathrm{c}$ & $\mathrm{c}$ & 1.6 & 0.3 & 15.0 & -331.7 \\
\hline 5 & & TS6e & $S i$ & $\mathrm{~g}$ & $\mathrm{t}$ & $\mathrm{c}$ & $\mathrm{c}$ & 1.4 & 0.6 & 8.6 & -313.4 \\
\hline 6 & & TS6f & $S i$ & $\mathrm{~d}$ & $\mathrm{t}$ & $\mathrm{t}$ & $\mathrm{c}$ & 2.5 & 0.9 & 4.8 & -321.6 \\
\hline 7 & & TS6g & $S i$ & $g$ & $\mathrm{t}$ & $\mathrm{c}$ & $\mathrm{t}$ & 2.4 & 1.5 & 1.9 & -313.8 \\
\hline 8 & & TS6h & $S i$ & $\mathrm{~d}$ & $\mathrm{t}$ & $\mathrm{c}$ & $\mathrm{t}$ & 2.9 & 1.6 & 1.7 & -330.8 \\
\hline 9 & & TS6i & $R e$ & $\mathrm{a}$ & $\mathrm{t}$ & $\mathrm{c}$ & $\mathrm{c}$ & 3.3 & 1.8 & 1.1 & -276.5 \\
\hline 10 & & TS6j & $R e$ & $\mathrm{~g}$ & $\mathrm{t}$ & $\mathrm{t}$ & $\mathrm{t}$ & 1.8 & 1.9 & 0.9 & -297.2 \\
\hline 11 & & TS6k & $R e$ & $g$ & $\mathrm{c}$ & $\mathrm{c}$ & $\mathrm{c}$ & 4.0 & 2.0 & 0.8 & -291.0 \\
\hline 12 & & TS61 & $S i$ & $\mathrm{~d}$ & $\mathrm{t}$ & $\mathrm{t}$ & $\mathrm{t}$ & 3.4 & 2.2 & 0.6 & -317.3 \\
\hline 13 & & TS6m & $S i$ & $\mathrm{~g}$ & $\mathrm{t}$ & $\mathrm{t}$ & $\mathrm{t}$ & 3.7 & 2.6 & 0.3 & -318.4 \\
\hline 14 & & TS6n & $R e$ & $\mathrm{a}$ & $\mathrm{t}$ & $\mathrm{t}$ & $\mathrm{c}$ & 4.2 & 2.7 & 0.3 & -277.4 \\
\hline 15 & & TS6o & $S i$ & $\mathrm{~d}$ & $\mathrm{c}$ & $\mathrm{c}$ & c & 4.3 & 3.4 & 0.1 & -321.6 \\
\hline 16 & & TS6p & $R e$ & $\mathrm{~g}$ & $\mathrm{c}$ & $\mathrm{c}$ & $\mathrm{t}$ & 5.1 & 3.8 & 0.0 & -296.0 \\
\hline 17 & & TS6q & $S i$ & $\mathrm{~d}$ & $\mathrm{c}$ & $\mathrm{t}$ & $\mathrm{c}$ & 4.9 & 4.0 & 0.0 & -321.4 \\
\hline 18 & & TS6r & $S i$ & $\mathrm{~d}$ & $\mathrm{c}$ & $\mathrm{c}$ & $\mathrm{t}$ & 5.1 & 4.0 & 0.0 & -323.2 \\
\hline 19 & $2 c$ & TS6s & $R e$ & $\mathrm{~g}$ & $\mathrm{t}$ & $\mathrm{c}$ & c & 5.1 & 5.0 & 0.0 & -254.6 \\
\hline 20 & $1 b$ & TS5a & $R e$ & $\mathrm{a}$ & $\mathrm{t}$ & $\mathrm{c}$ & $\mathrm{c}$ & 14.2 & 13.2 & 0.0 & -386.4 \\
\hline 21 & $1 c$ & TS5b & $R e$ & $\mathrm{a}$ & $\mathrm{c}$ & $\mathrm{t}$ & $\mathrm{c}$ & 19.5 & 19.4 & 0.0 & -552.8 \\
\hline
\end{tabular}

${ }^{a}$ Only those below $4 \mathrm{kcal} \mathrm{mol}^{-1}$ of relative free energy in the $2 \zeta$ study have been considered for the triple- $\zeta$ one (see text). ${ }^{b}$ Referred to the tautomer that reacts with $6 .{ }^{c}$ Indicates the face of the oxime/nitrone. ${ }^{d}$ Three staggered orientations of the oxime/nitrone attack to 6, defined as "d" (droite), "g" (gauche) and "a" (anti); see ESI for definition of $\mathrm{d} / \mathrm{g} / \mathrm{a}$. ${ }^{e}$ "c" and "t" correspond to s-cis and s-trans conformations of the considered dihedral angles of 6. ${ }^{f}$ With respect to the most stable one. ${ }^{g}$ According to Boltzmann's distribution. 

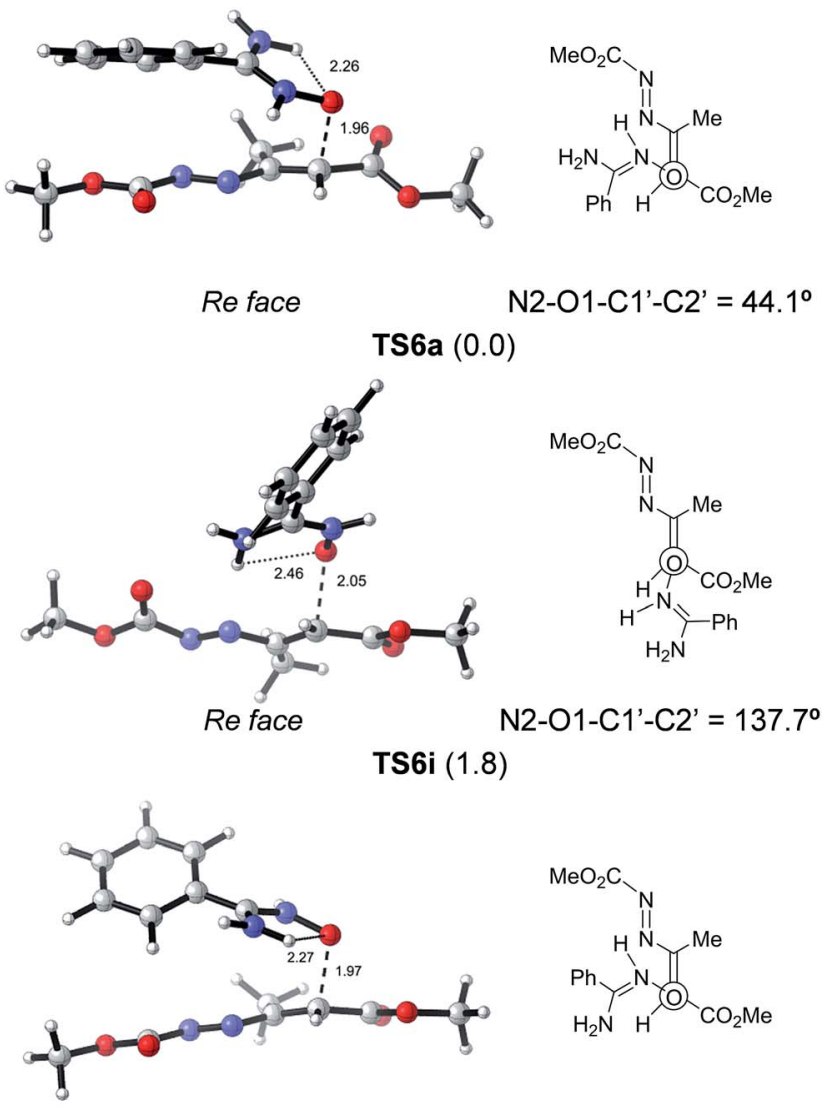

Si face

$$
\mathrm{N} 2-\mathrm{O} 1-\mathrm{C} 1^{\prime}-\mathrm{C} 2^{\prime}=13.0^{\circ}
$$

TS6e (0.6)

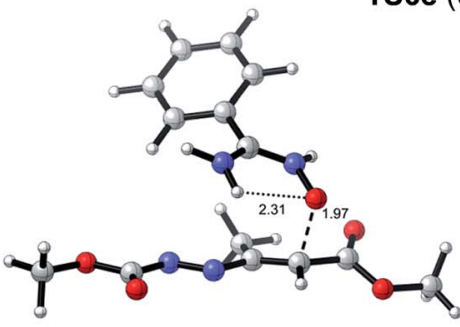

$\mathrm{MeO}_{2} \mathrm{C}$

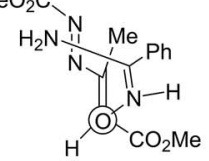

Si face

$\mathrm{N} 2-\mathrm{O} 1-\mathrm{C} 1^{\prime}-\mathrm{C} 2^{\prime}=-33.1^{\circ}$

TS6d (0.3)

Fig. 5 Selected optimized transition structures (M06-2X/cc-pVTZ/ $\mathrm{PCM}=\mathrm{EtOH}$ ) corresponding to the nucleophilic attack of $2 b$ to 6 . The more stable TSs for each approach are showed. Relative energies are given in $\mathrm{kcal} \mathrm{mol}^{-1}$. Distances are given in angstroms.

nitrone $2 \mathrm{c}$ was found to be $5.0 \mathrm{kcal} \mathrm{mol}{ }^{-1}$ higher in energy. The most stable TSs, TS5a and TS5b, corresponding to the addition of oxime tautomers gave even higher energy values (by 13.2 and $19.4 \mathrm{kcal} \mathrm{mol}^{-1}$ for $(Z)$-oxime $\mathbf{1 b}$ and $(E)$-oxime 1c, respectively).

Fig. 6 illustrates the compared simplified energy diagrams for the different isomers showing the energy barriers for the reaction of each isomer. Different final points (not shown in Fig. 6) were obtained for each reaction path; after tautomeric processes those points led to either $\mathbf{7 b}$ or $\mathbf{7 c}$, the most stable tautomers (for complete energy diagrams, transition structures and full reaction paths see $\mathrm{ESI} \dagger$ ).

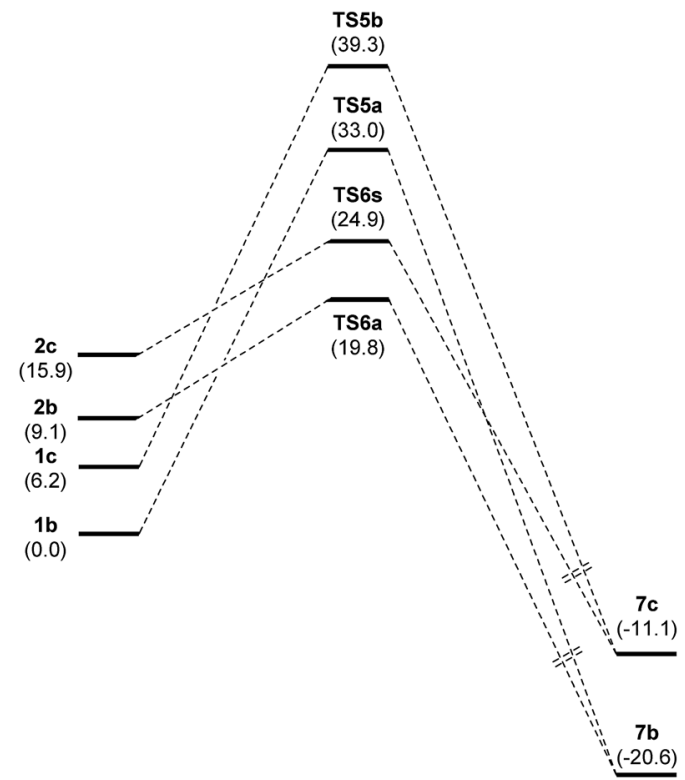

Fig. 6 Simplified free energy diagrams (M06-2X/CC-PVTZ/PCM = $\mathrm{EtOH})$ for the nucleophilic addition of oximes $1 b, c$ and nitrones $2 b, c$ to 1,2-diaza-1,3-diene 6. TS5a and TS5b correspond to (Z)- and (E)oximes, respectively. TS6a and TS6b correspond to (Z)- and (E)nitrones, respectively.

To sum up, even though isomerization of oxime $\mathbf{1 b}$ to nitrone $2 \mathbf{b}$ has a barrier of $15.3 \mathrm{kcal} \mathrm{mol}^{-1}$ and requires a cost in energy of $9.2 \mathrm{kcal} \mathrm{mol}^{-1}$, the most stable transition state is that corresponding to the attack of the nitrone tautomer through TS6a. According to the Curtin-Hammett principle ${ }^{\mathbf{4 1}}$ this is the preferred path for the reaction, revealing a rare case in which a nitrone tautomer participates in a nucleophilic addition reaction.

\section{Ene-like reactions and alternative processes}

As we discussed in the introduction, ene-like reaction between $\mathbf{1 b}$ and $\mathbf{6}$ (path A, Scheme 2) and dipolar cycloaddition between 2b and 6 (path D, Scheme 2), could be competitive with the nucleophilic Michael addition. In order to validate our model and further confirm the preference by the nitrone-mode addition, we also calculated those alternative paths of the reaction.

The possibility of an ene-like reaction (Scheme 2, path A) was first explored. A typical transition structure $\mathbf{T S}_{\mathbf{A}}$ could be located in a simple model like addition of $\mathbf{1 b}$ to dimethyl 2-methylfumarate. ${ }^{42}$ The IRC analysis corroborated that the reaction was concerted and transfer of hydrogen takes place giving rise to the corresponding nitrone (see ESI $\dagger$ ).

On the other hand, the reaction with 1,2-diaza-1,3-diene 6 led to dramatic changes on the located transition structures. A full exploration of the PES corresponding to the nucleophilic attack of the oxime nitrogen was carried out by considering $\mathbf{1 b}$ and 1c as well as s-trans-6 and s-cis-6 (for details see ESI $\dagger$ ).

No transition structures corresponding to an H-transfer to the carbon atom through a concerted ene-like process could be located; instead, in all cases the hydrogen atom was oriented to the formation of an $\mathrm{H}$-bond either with one of the nitrogen 
atoms of the diazo group or the carbonyl ester group directly linked to the double bond. The most stable paths were those showed in Scheme 9. TS7b was $0.6 \mathrm{kcal} \mathrm{mol}^{-1}$ lower in energy than TS8 (energy barriers: 20.6 and $21.2 \mathrm{kcal} \mathrm{mol}^{-1}$ for TS7b and TS8, respectively) so, both transition structures can be considered competitive. Transition structure TS7b does not correspond to an ene-like process and the IRC analysis confirmed a partial hydrogen transfer. The resulting zwitterion $\mathbf{P 4 b}$ is assumed to be transformed into the neutral nitrone $9 \mathrm{~b}$ through a typical tautomeric process. In the case of s-cis-6, IRC of TS8 reflects a complete transfer of hydrogen to the diazo group, leading directly to the neutral nitrone. Any attempt of locating an ene-like transition structure similar to that located for the model methyl 2-methylfumarate, led to one of the TSs located previously during PES exploration (see ESI $\dagger$ ).

The free energy barriers found for TS7b, and TS8 were 0.8 and $1.4 \mathrm{kcal} \mathrm{mol}^{-1}$, respectively, higher in energy than the most stable TS6a (Fig. 7). These values indicate that the nucleophilic addition is preferred in agreement with experimental observations. However, it should also be considered that both processes might be competitive since the differences observed between barrier values are within the error limit of the calculations. Nevertheless, it would not be surprising that a close inspection of the reaction mixture could reveal the obtention of minor amounts of nitrone $\mathbf{9 b}$.

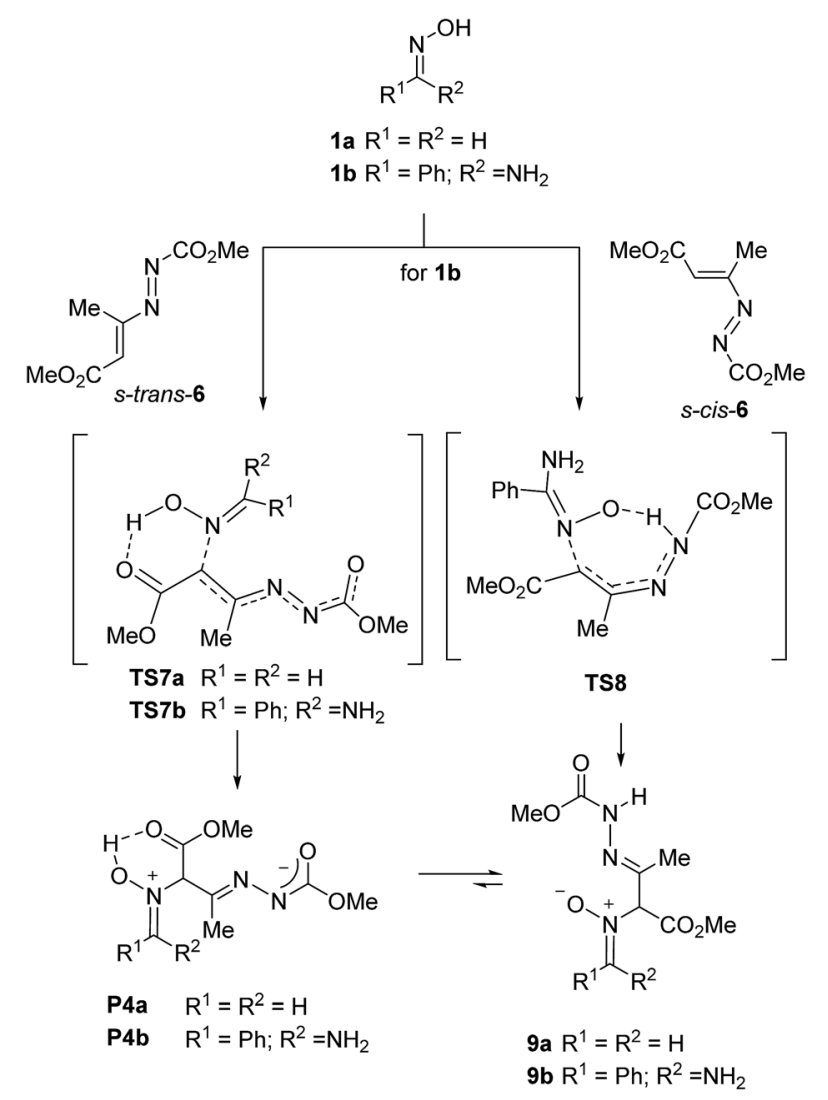

Scheme 9 Preferred path for the nucleophilic attack of the oxime nitrogen.

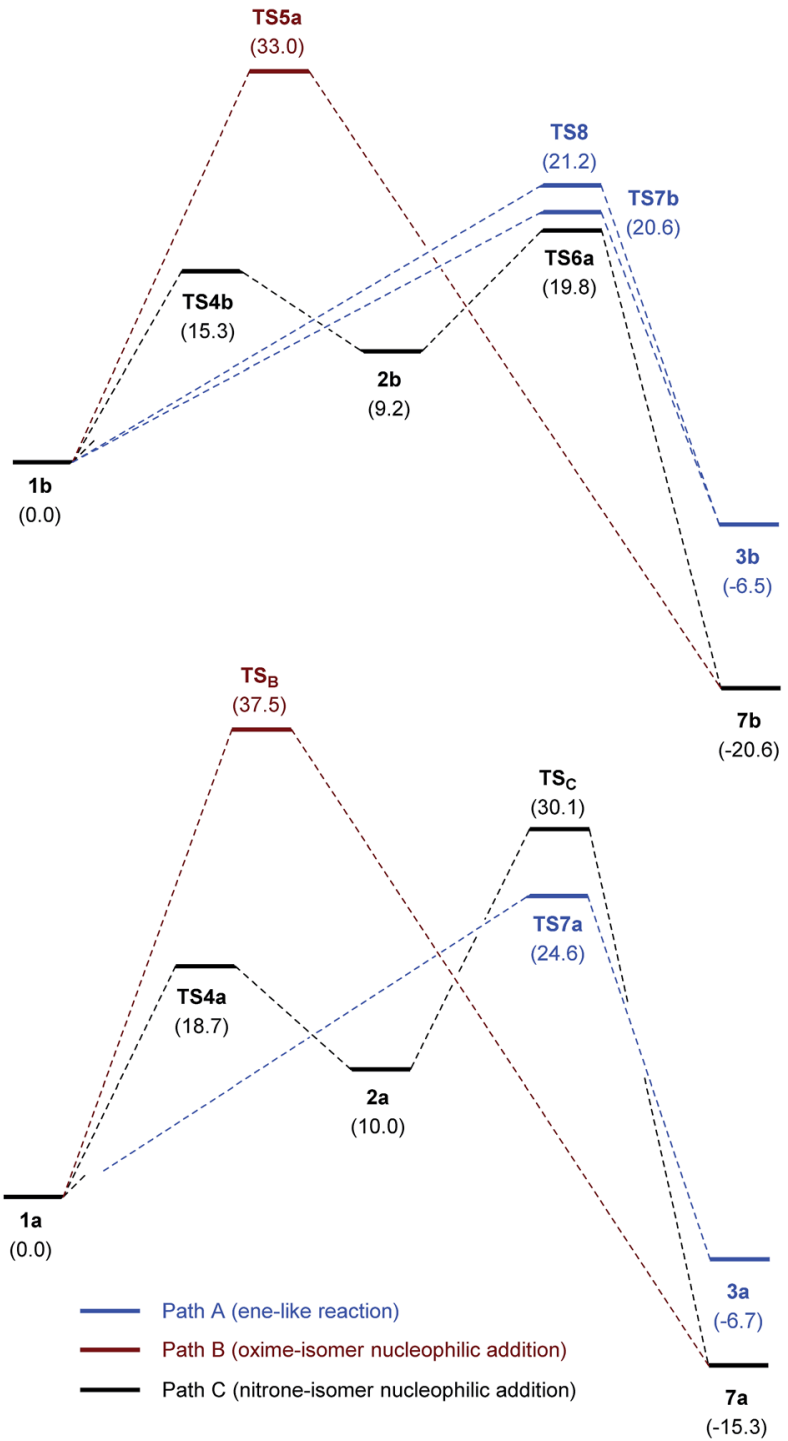

Fig. 7 Comparative free energy diagrams (M06-2X/cc-pVTZ/PCM = $\mathrm{EtOH}$ ) for the reaction between $1 \mathrm{~b}$ and 6 (top) and $1 \mathrm{a}$ and 6 (bottom). Relative free energies are given in $\mathrm{kcal} \mathrm{mol}^{-1}$.

When the same study was made with the unsubstituted oxime 1a, the nucleophilic addition of the oxime nitrogen leading to the nitrone through TS7a, clearly resulted the most stable situation $\left(5.5 \mathrm{kcal} \mathrm{mol}^{-1}\right.$ lower in energy than the corresponding transition structure $\mathbf{T S}_{\mathbf{C}}$; see ESI $\dagger$ ) in agreement with previous experimental findings with aldoximes and revealing the particularity of oxime 1b (Fig. 7). These results allow predicting that, in general and in the absence of a base, the ene-like process (Scheme 2, path A) should be preferred for the reaction of an oxime and an electron-poor alkene, but when steric hindrance is present as in the case of ketoximes like $\mathbf{1 b}$, the $O$-alkylation is a competitive process taking place through the attack of the nitrone tautomer (Scheme 2, path C).

The reason of the different results obtained with $\mathbf{1 a}$ and $\mathbf{1 b}$ can be found in the different spatial requirements of both oximes. The geometries of transition structures TS7b, TS8 and TS7a are given in Fig. 8. The unsubstituted oxime 1a attacks 


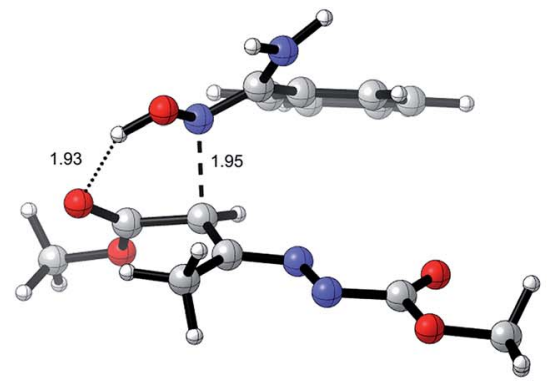

TS7b

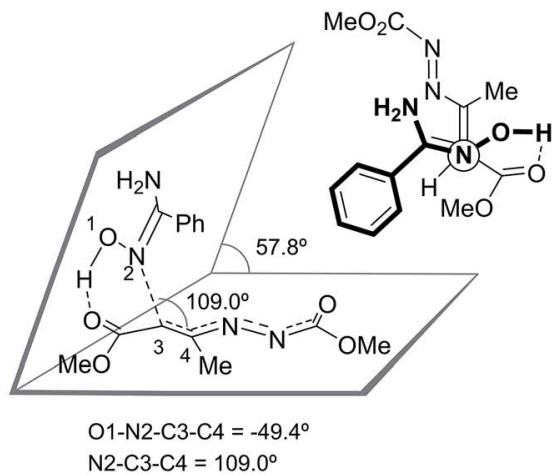

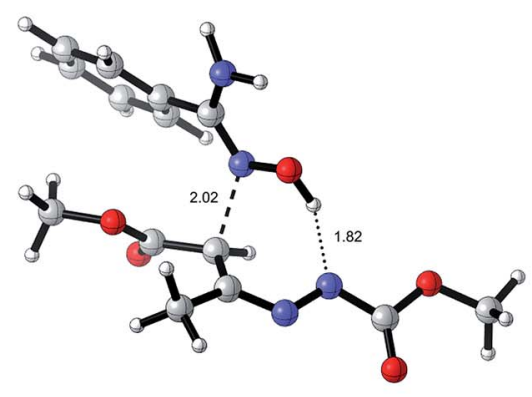

TS8

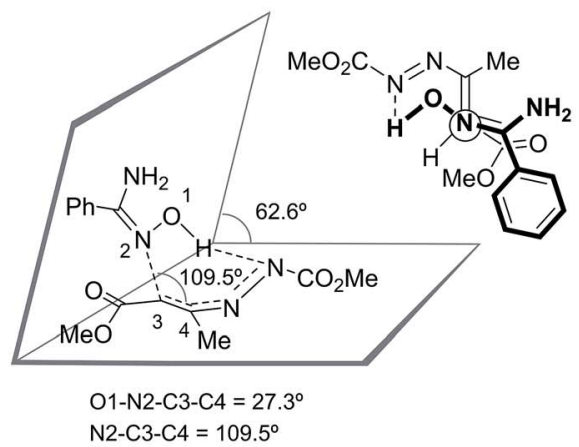

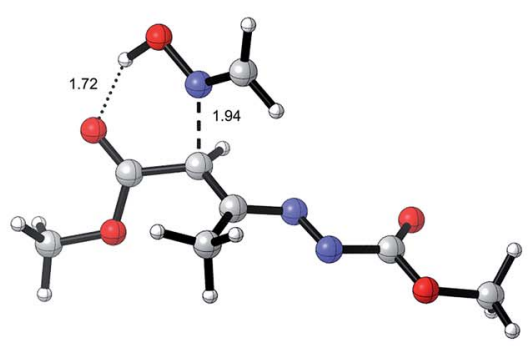

TS7a

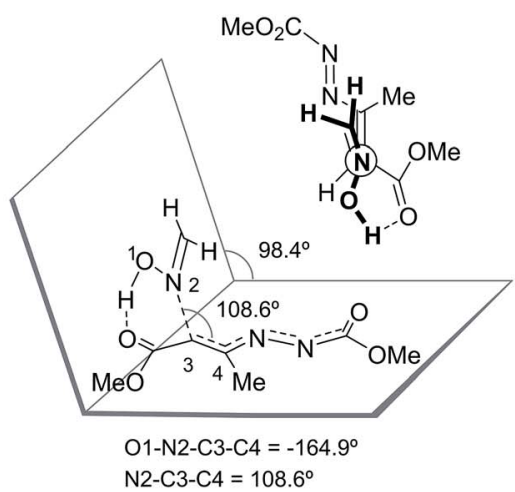

Fig. 8 Optimized transition structures (M06-2X/cc-pVTZ/PCM =EtOH) of TS7b and TS8 corresponding to the ene-like reaction between oxime $1 \mathrm{~b}$ and 1,2-diaza-1,3-diene 6, and TS7a corresponding to the reaction between $1 \mathrm{a}$ and 6 . Distances are given in angstrom.

with a correct orientation of the nitrogen lone pair, through a completely perpendicular eclipsed orientation (O1-N2-C3-C4 dihedral angle of $-164.9^{\circ}$ ) following a typical Burgi-Dunitz trajectory (N2-C3-C4 angle of $108.6^{\circ}$ ). The perpendicularity of the oxime with respect to the 1,2-diaza-1,3-diene is evidenced by the angle of $98.4^{\circ}$ formed between the reactant planes defined by the oxime and the diazadiene (Fig. 8). ${ }^{43}$ On the other hand, oxime $\mathbf{1 b}$ is forced to modify such orientation in order to maintain the Burgi-Dunitz trajectory (N2-C3-C4 angles of $109.0^{\circ}$ and $109.5^{\circ}$ for TS7b and TS8, respectively) and, at the same time, to avoid unfavorable steric interactions. As a consequence, the nitrogen lone pair is not perfectly aligned with the carbon atom and the situation increases the energy of the corresponding transition structures. The distorsion during the attack of $\mathbf{1 b}$ is revealed by the steeper angles formed between the planes defined by the oxime and the diazadiene $\left(57.8^{\circ}\right.$ and $62.6^{\circ}$ for TS7b and TS8, respectively) with respect to that observed for 1a.

Finally, no concerted transition structures corresponding to path D (Scheme 2) could be located. Moreover, any attempt of locating such concerted transition structures led to some of the already characterized TSs listed in Table 5. In particular, a systematic search and optimization for initial 3,5-endo and 3,5-exo transition structures led to TS6d and TS6a, respectively.

\section{Conclusions}

The oxime-nitrone isomerization has been studied computationally and it has been determined that it takes place through a bimolecular mechanism involving two molecules of oxime (or nitrone). The commonly accepted $1,2-\mathrm{H}$ shift can be completely discarded, even if favored by neighboring groups, due to the high energies of the corresponding transition structures. Oximes usually react with electron deficient olefins to give the corresponding nitrones through $N$-alkylation (formal Michael addition) and concomitant hydrogen transfer. The mechanism of the reaction had been proposed to be an ene-like concerted process and it has been confirmed in the case of a simple model.

The $O$-alkylation observed experimentally in the reaction of oxime $\mathbf{1 b}$ to 1,2-diaza-1,3-diene $\mathbf{6}$, in the absence of a base, can be considered an exception. The computational study carried out on this process has demonstrated that the reaction takes place through the nucleophilic attack of the nitrone tautomer. The addition represents the first example in which the nitrone tautomer is involved into a nucleophilic addition of an oxime. Nevertheless, the $N$-alkylation should be considered a competitive process. Indeed, it can also be predicted that $O$-alkylation (though nitrone tautomer) will take place particularly with sterically demanding substrates such as ketoximes like the studied 1b. In the case of substrates that allow a favorable orthogonal approach of the oxime to the electron deficient alkene, the $N$-alkylation leading to the corresponding nitrone will be preferred.

\section{Acknowledgements}

This work was supported by the Spanish Ministerio de Economía y Competitividad (MINECO) (project number CTQ201344367-C2-1-P), by the Fondos Europeos para el Desarrollo 
Regional (FEDER) and the Gobierno de Aragón (Zaragoza, Spain, Bioorganic Chemistry Group, E-10). The authors acknowledge the Institute of Biocomputation and Physics of Complex Systems (BIFI) at the University of Zaragoza for computer time at clusters Terminus and Memento. D. R.-L. thanks the Spanish Ministry of Education (MEC) for a predoctoral grant (FPU program).

\section{Notes and references}

1 P. C. Vijfhuizen and J. K. Terlouw, Org. Mass Spectrom., 1977, $12,63$.

2 K. J. Dignam and A. F. Hegarty, J. Chem. Soc., Perkin Trans. 2, 1979, 1437.

3 (a) R. Grigg, H. Q. N. Gunaratne and J. Kemp, J. Chem. Soc., Perkin Trans. 1, 1984, 41; (b) R. Grigg, M. Jordan, A. Tangthongkum, F. W. B. Einstein and T. Jones, J. Chem. Soc., Perkin Trans. 1, 1984, 47; (c) R. Grigg, Chem. Soc. Rev., 1987, 16, 89.

4 (a) M. Noguchi, S. Nishimura, H. Fujii and A. Kakehi, Heterocycl. Commun., 1999, 5, 133; (b) S. Moutel and M. Shipman, Synlett, 1998, 1333; (c) C. A. D. Sousa, M. L. C. Vale, X. Garcia-Mera and J. E. Rodriguez-Borges, Tetrahedron, 2012, 68, 1682; (d) P. Armstrong, R. Grigg and W. J. Warnock, J. Chem. Soc., Chem. Commun., 1987, 1325; (e) U. Chiacchio, A. Corsaro, D. Iannazzo, A. Piperno, V. Pistara, A. Rescifina, R. Romeo, G. Sindona and G. Romeo, Tetrahedron: Asymmetry, 2003, 14, 2717; $(f)$ J. A. Rincon, C. Mateos, P. Garcia-Losada and D. J. Mergott, Org. Process Res. Dev., 2015, 19, 347; (g) C. A. D. Sousa, J. E. Rodriguez-Borges and X. Garcia-Mera, Tetrahedron Lett., 2014, 55, 4628; (h) E. Frank, Z. Mucsi, M. Szecsi, I. Zupko, J. Woelfling and G. Schneider, New J. Chem., 2010, 34, 2671; (i) C. W. Lee, J. Y. Park, H. Kim and K.-W. Chi, Bull. Korean Chem. Soc., 2010, 31, 1172-1176.

5 (a) A. Hassner and R. Maurya, Tetrahedron Lett., 1989, 30, 5803; (b) A. Hassner, R. Maurya, A. Padwa and W. H. Bullock, J. Org. Chem., 1991, 56, 2775; (c) A. Hassner, R. Maurya, O. Friedman, H. E. Gottlieb, A. Padwa and D. Austin, J. Org. Chem., 1993, 58, 4539; (d) A. Hassner, K. M. L. Rai and W. Dehaen, Synth. Commun., 1994, 24, 1669; (e) E. Falb, Y. Bechor, A. Nudelman, A. Hassner, A. Albeck and H. E. Gottlieb, J. Org. Chem., 1999, 64, 498; (f) G. V. M. Sharma, I. S. Reddy, V. G. Reddy and A. V. R. Rao, Tetrahedron: Asymmetry, 1999, 10, 229; $(g)$ A. Bhattacharjee, S. Datta, P. Chattopadhyay, N. Ghoshal, A. P. Kundu, A. Pal, R. Mukhopadhyay, S. Chowdhury, A. Bhattacharjya and A. Patra, Tetrahedron, 2003, 59, 4623; (h) L. Gottlieb, A. Hassner and H. E. Gottlieb, Synth. Commun., 2000, 30, 2445; (i) L. Doyle and F. Heaney, Tetrahedron, 2010, 66, 7041; (j) F. Heaney, J. Fenlon, C. O'Mahony, P. McArdle and D. Cunningham, Org. Biomol. Chem., 2003, 1, 4302.

6 (a) R. Grigg, J. Markandu, T. Perrior, S. Surendrakumar and W. J. Warnock, Tetrahedron, 1992, 48, 6929; (b) M. Noguchi, S. Matsumoto, M. Shirai and H. Yamamoto, Tetrahedron, 2003, 59, 4123.
7 (a) O. Tamura, T. Mitsuya and H. Ishibashi, Chem. Commun., 2002, 1128; (b) O. Tamura, N. Iyama and H. Ishibashi, J. Org. Chem., 2004, 69, 1475; (c) O. Tamura, T. Mitsuya, X. Huang, Y. Tsutsumi, S. Hattori and H. Ishibashi, J. Org. Chem., 2005, 70, 10720.

8 (a) O. Tamura, N. Morita, Y. Takano, K. Fukui, I. Okamoto, X. Huang, Y. Tsutsumi and H. Ishibashi, Synlett, 2007, 658; (b) N. Morita, K. Fukui, J. Irikuchi, H. Sato, Y. Takano, I. Okamoto, H. Ishibashi and O. Tamura, J. Org. Chem., 2008, 73, 7164; (c) N. Morita, R. Kono, K. Fukui, A. Miyazawa, H. Masu, I. Azumaya, S. Ban, Y. Hashimoto, I. Okamoto and O. Tamura, J. Org. Chem., 2015, 80, 4797; (d) N. Morita, R. Kono, K. Fukui, A. Miyazawa, H. Masu, I. Azumaya, S. Ban, Y. Hashimoto, I. Okamoto and O. Tamura, J. Org. Chem., 2015, 80, 4797.

9 (a) E. Frank, Z. Mucsi, M. Szecsi, I. Zupko, J. Wolflingg and G. Schneider, New J. Chem., 2010, 34, 2671; (b) A. K. Nacereddine, H. Layeb, F. Chafaa, W. Yahia, A. Djerourou and L. R. Domingo, RSC Adv., 2015, 5, 64098.

10 (a) P. Merino, in Science of Synthesis, ed. E. Schaumann, George Thieme, Stuttgar, 2011, vol. 2010/4, p. 325; (b) P. Merino, in Science of Synthesis, ed. D. Bellus and A. Padwa, George Thieme, Stuttgart, 2004, vol. 27, p. 511; (c) R. Matute, S. Garcia-Viñuales, H. Hayes, M. Ghirardello, A. Daru, T. Tejero, I. Delso and P. Merino, Curr. Org. Synth., 2015, DOI: 10.2174/1570179412666150914200035.

11 (a) M. Noguchi, H. Okada, M. Tanaka, S. Matsumoto, A. Kakehi and H. Yamamoto, Bull. Chem. Soc. Jpn., 2001, 74, 917; (b) M. Noguchi, H. Okada, S. Nishimura, Y. Yamagata, S. Takamura, M. Tanaka, A. Kakehi and H. Yamamoto, J. Chem. Soc., Perkin Trans. 1, 1999, 185; (c) I. Walton, M. Davis, L. Yang, Y. Zhang, D. Tillman, W. L. Jarrett, M. T. Huggins and K. J. Wallace, Magn. Res. Chem., 2011, 49, 205; (d) F. Heaney, S. Bourke, D. Cunningham and P. McArdle, J. Chem. Soc., Perkin Trans. 2, 1998, 547; (e) F. Heaney and S. Bourke, J. Chem. Soc., Perkin Trans. 1, 1998, 955.

12 M. Gotoh, T. Mizui, B. Sun, K. Hirayama and M. Noguchi, J. Chem. Soc., Perkin Trans. 1, 1995, 1857.

13 (a) M. Gotoh, B. Sun, K. Hirayama and M. Noguchi, Tetrahedron, 1996, 52, 887; (b) F. Heaney and C. O'Mahony, J. Chem. Soc., Perkin Trans. 1, 1998, 341; (c) C. O'Mahony and F. Heaney, Chem. Commun., 1996, 167.

14 M. Shirai, H. Kuwabara, S. Matsumoto, H. Yamamoto, A. Kakehi and M. Noguchi, Tetrahedron, 2003, 59, 4113.

15 J. E. Reimann and W. P. Jencks, J. Am. Chem. Soc., 1966, 88, 3973.

16 P. D. Adeney, W. J. Bouma, L. Radom and W. R. Rodwell, J. Am. Chem. Soc., 1980, 102, 4069.

17 J. A. Long, N. J. Harris and K. Lammertsma, J. Org. Chem., 2001, 66, 6762.

18 C. A. D. Sousa, M. L. C. Vale, X. Garcia-Mera and J. E. Rodríguez-Borges, Tetrahedron, 2012, 68, 1682.

19 (a) A. G. Moglioni, E. Muray, J. A. Castillo, A. Alvarez-Larena, G. Y. Moltrasio, V. Branchadell and R. M. Ortuno, J. Org. Chem., 2002, 67, 2402; (b) J. Moran, J. Y. Pfeiffer, 
S. I. Gorelsky and A. M. Beauchemin, Org. Lett., 2009, 11, 1895.

20 (a) H. M. Meshram, B. Eeshwaraiah, M. Sreenivas, D. Aravind, B. S. Sundar and J. S. Yadav, Synth. Commun., 2009, 39, 1857; (b) A. Pohjakallio and P. M. Pihko, Chem.Eur. J., 2009, 15, 3960; (c) B. Tan, Z. Shi, P. J. Chua, Y. Li and G. Zhong, Angew. Chem., Int. Ed., 2009, 48, 758; (d) T. J. Martin, V. G. Vakhshori, Y. S. Tran and O. Kwon, Org. Lett., 2011, 13, 2586; (e) A. Carlone, G. Bartoli, M. Bosco, F. Pesciaioli, P. Ricci, L. Sambori and P. Melchiorre, Eur. J. Org. Chem., 2007, 5492.

21 O. A. Attanasi, L. Cotarca, G. Favi, P. Filippone, F. R. Perrulli and S. Santeusanio, Synlett, 2009, 1583.

22 (a) D. Roca-López, V. Polo, T. Tejero and P. Merino, J. Org. Chem., 2015, 80, 4076; (b) D. Roca-López, T. Tejero and P. Merino, J. Org. Chem., 2014, 79, 8358; (c) P. Merino, T. Tejero and A. Diez Martinez, J. Org. Chem., 2014, 79, 2189; (d) D. Roca-López, V. Polo, T. Tejero and P. Merino, Eur. J. Org. Chem., 2015, 4143; (e) D. Roca-López, T. Tejero, P. Caramella and P. Merino, Org. Biomol. Chem., 2014, 12, 517; (f) A. Daru, D. Roca-López, T. Tejero and P. Merino, J. Org. Chem., 2016, 81, 673.

23 M. J. Frisch, G. W. Trucks, H. B. Schlegel, G. E. Scuseria, M. A. Robb, J. R. Cheeseman, G. Scalmani, V. Barone, B. Mennucci, G. A. Petersson, H. Nakatsuji, M. Caricato, X. Li, H. P. Hratchian, A. F. Izmaylov, J. Bloino, G. Zheng, J. L. Sonnenberg, M. Hada, M. Ehara, K. Toyota, R. Fukuda, J. Hasegawa, M. Ishida, T. Nakajima, Y. Honda, O. Kitao, H. Nakai, T. Vreven, J. Montgomery Jr, J. E. Peralta, F. Ogliaro, M. Bearpark, J. J. Heyd, E. Brothers, K. N. Kudin, V. N. Staroverov, R. Kobayashi, J. Normand, K. Raghavachari, A. Rendell, J. C. Burant, S. S. Iyengar, J. Tomasi, M. Cossi, N. Rega, J. M. Millam, M. Klene, J. E. Knox, J. B. Cross, V. Bakken, C. Adamo, J. Jaramillo, R. Gomperts, R. E. Stratmann, O. Yazyev, A. J. Austin, R. Cammi, C. Pomelli, J. W. Ochterski, R. L. Martin, K. Morokuma, V. G. Zakrzewski, G. A. Voth, P. Salvador, J. J. Dannenberg, S. Dapprich, A. D. Daniels, Ö. Farkas, J. B. Foresman, J. V. Ortiz, J. Cioslowski and D. J. Fox, Gaussian, Wallingford, CT, 2009.

24 Y. Zhao and D. G. Truhlar, Acc. Chem. Res., 2008, 41, 157.

25 (a) T. H. Dunning Jr., J. Chem. Phys., 1989, 90, 1007; (b) R. A. Kendall, T. H. Dunning Jr. and R. J. Harris, J. Chem. Phys., 1992, 96, 6796; (c) D. E. Woon and T. H. Dunning Jr., J. Chem. Phys., 1993, 98, 1358; (d) E. Papajak, J. Zheng; $\mathrm{X} . \mathrm{Xu}, \mathrm{H}$. R. Leverentz and D. G. Truhlar, J. Chem. Theory Comput., 2011, 7, 3027.

26 (a) K. Fukui, J. Phys. Chem., 1970, 74, 4161; (b) K. Fukui, Acc. Chem. Res., 1981, 14, 363.

27 (a) C. González and H. B. Schlegel, J. Phys. Chem., 1990, 94, 5523; (b) C. González and H. B. Schlegel, J. Chem. Phys., 1991, 95, 5853.
28 (a) M. Cossi, V. Barone, R. Cammi and J. Tomasi, Chem. Phys. Lett., 1996, 255, 327; (b) E. Cances, B. Mennucci and J. Tomasi, J. Chem. Phys., 1997, 107, 3032; (c) V. Barone, M. Cossi and J. Tomasi, J. Comput. Chem., 1998, 19, 404; (d) J. Tomasi and M. Persico, Chem. Rev., 1994, 94, 2027.

29 J. Galvez and A. Guirado, J. Comput. Chem., 2010, 31, 520.

30 R. Grigg, F. Heaney, J. Markandu, S. Surendrakumar, M. Thornton-Pett and W. J. Warnock, Tetrahedron, 1991, 47, 4007.

31 R. Jasinski, Comput. Theor. Chem., 2014, 1046, 93-98.

32 R. Grigg and S. Thianpantangul, J. Chem. Soc., Perkin Trans. 1, 1984, 653.

33 H.-X. Zhou and M. K. Gilson, Chem. Rev., 2009, 109, 4902.

34 The prediction of accurate Gibbs free energy values for medium systems in solution remains a challenge for present-day DFT methods. The absolute errors might be significant for association/dissociation steps; however, for isomeric processes, favorable error cancellation is expected, leading to smaller relative errors as compared to their absolute values.

35 Considering that in the experimental conditions ethanol is the solvent, the formation of the oxime pair $\mathbf{1} \cdot \mathbf{1}$ requires desolvation of two molecules of oxime which is not necessary in the ethanol-assisted mechanism. However, it is also necessary to consider the additional solvation energy of the newly formed oxime dimer, which compensate desolvation of oximes $\mathbf{1}$ (for a detailed analysis of the situation see ESI $\dagger$ ).

36 (a) S. Mantenuto, F. Mantellini, G. Favi and O. A. Attanasi, Org. Lett., 2015, 17, 2014; (b) L. De Crescentini, O. A. Attanasi, L. A. Campisi, G. Favi, S. Lillini, F. Ursini and F. Mantellini, Tetrahedron, 2015, 71, 7282; (c) E. Juhasz-Toth, G. Favi, O. A. Attanasi, A. C. Benyei and T. Patonay, Synlett, 2014, 25, 2001.

37 R. Majer, O. Konechnaya, I. Delso, T. Tejero, O. A. Attanasi, S. Santeusanio and P. Merino, Org. Biomol. Chem., 2014, 12, 8888 .

38 E. M. Brasil, R. S. Borges, O. A. S. Romero, C. N. Alves, J. A. Saez and L. R. Domingo, Tetrahedron, 2012, 68, 6902.

39 For a complete conformational analysis of 6 see ESI $\dagger$

40 Actually, entries 19-21 were selected after optimization of similar structures within a range of $2 \mathrm{kcal} \mathrm{mol}^{-1}$ to ensure that the most stable situations are chosen.

41 J. I. Seeman, Chem. Rev., 1983, 83, 83.

42 We initially used this model because it represents the exchange of the methoxycarbonyldiazo group by a simple ester group. For details see ESI†

43 The dihedral angle between those planes has been found by: (1) calculating the equation for each plane from cartesian atomic cooordinates of three atoms of oxime and three atoms of 1,2-diaza-1,3-diene, and (2) calculating the corresponding angle determined by the normal vectors of the planes. 